\title{
The placebo response rate in pharmacological trials in patients with irritable bowel syndrome: a systematic review and meta-analysis
}

Citation for published version (APA):

Bosman, M., Elsenbruch, S., Corsetti, M., Tack, J., Simren, M., Winkens, B., Boumans, T., Masclee, A., \& Keszthelyi, D. (2021). The placebo response rate in pharmacological trials in patients with irritable bowel syndrome: a systematic review and meta-analysis. The Lancet Gastroenterology and Hepatology, 6(6), 459-473. https://doi.org/10.1016/S2468-1253(21)00023-6

Document status and date:

Published: 01/06/2021

DOI:

10.1016/S2468-1253(21)00023-6

Document Version:

Publisher's PDF, also known as Version of record

Document license:

Taverne

Please check the document version of this publication:

- A submitted manuscript is the version of the article upon submission and before peer-review. There can be important differences between the submitted version and the official published version of record.

People interested in the research are advised to contact the author for the final version of the publication, or visit the DOI to the publisher's website.

- The final author version and the galley proof are versions of the publication after peer review.

- The final published version features the final layout of the paper including the volume, issue and page numbers.

Link to publication

\footnotetext{
General rights rights.

- You may freely distribute the URL identifying the publication in the public portal. please follow below link for the End User Agreement:

www.umlib.nl/taverne-license

Take down policy

If you believe that this document breaches copyright please contact us at:

repository@maastrichtuniversity.nl

providing details and we will investigate your claim.
}

Copyright and moral rights for the publications made accessible in the public portal are retained by the authors and/or other copyright owners and it is a condition of accessing publications that users recognise and abide by the legal requirements associated with these

- Users may download and print one copy of any publication from the public portal for the purpose of private study or research.

- You may not further distribute the material or use it for any profit-making activity or commercial gain

If the publication is distributed under the terms of Article $25 \mathrm{fa}$ of the Dutch Copyright Act, indicated by the "Taverne" license above, 


\section{The placebo response rate in pharmacological trials in patients with irritable bowel syndrome: a systematic review and meta-analysis}

Michelle Bosman, Sigrid Elsenbruch, Maura Corsetti, Jan Tack, Magnus Simrén, Bjorn Winkens, Thimo Boumans, Ad Masclee, Daniel Keszthelyi

\section{Summary}

Background Clinical trials in irritable bowel syndrome are associated with high placebo response rates. We aimed to identify the magnitude of the placebo response and the contributing factors to this occurrence.

Methods We did a systematic review and meta-analysis with a search of MEDLINE, EMBASE, and the Cochrane Central Register of Controlled Trials between April 1, 1959, and April 30, 2020. We included all randomised controlled trials that compared an active pharmacotherapeutic agent with placebo and had a dichotomous outcome of response to therapy (in terms of global improvement or improvement in abdominal pain) in adults (aged $\geq 18$ years) with irritable bowel syndrome. Exclusion criteria were trials reporting on treatment satisfaction as a dichotomous outcome of response to therapy or clinician-reported outcomes and a treatment duration of less than 4 weeks. Our main outcome was identification of the magnitude of the pooled placebo response rate for the following endpoints: global improvement, abdominal pain, and US Food and Drug Administration (FDA) endpoints. We extracted information from published reports and pooled proportions through meta-analysis with random effects. The study was registered with PROSPERO, CRD42020170908.

Findings Of the 6863 publications identified, 70 articles describing 73 randomised controlled trials were included in our analysis. The pooled placebo response rate was $27 \cdot 3 \%$ (95\% CI $24 \cdot 3-30 \cdot 9)$ using the global improvement endpoint, $34 \cdot 4 \%(31 \cdot 2-37 \cdot 8)$ using the abdominal pain endpoint, and $17 \cdot 9 \%(15 \cdot 2-21 \cdot 0)$ using the composite FDA endpoint responder definition, all with substantial heterogeneity between the trials. Studies published before 2006, and those done in Europe, with a parallel design, a run-in period of 2 weeks or less, a dose schedule of three times a day or more, or a smaller sample size of the control group were significantly associated with an increased pooled placebo response rate.

Interpretation More than a quarter of patients with irritable bowel syndrome had a placebo response in terms of global improvement, with multiple associated moderators. We recommend future trials apply a run-in period of at least 2 weeks and dose once or twice a day to minimise the placebo response rate.

Funding None.

Copyright (C) 2021 Published by Elsevier Ltd. All rights reserved.

\section{Introduction}

Irritable bowel syndrome (IBS) is a common disorder of gut-brain interaction characterised by recurrent abdominal pain associated with defecation or a change in bowel habits. ${ }^{1,2}$ The estimated prevalence in a recent study is $4.6 \%$ in the USA, Canada, and UK (according to the Rome IV criteria). ${ }^{3}$ IBS is not only associated with a substantial effect on an individuals' functioning and quality of life, but also with substantial costs to patients, health-care systems, and society. ${ }^{4.5}$ The treatment of IBS is commonly known to represent a clinical challenge, in part because of varying efficacy of different therapies. ${ }^{1,6}$ To improve therapeutic outcomes, more in-depth understanding of the mechanisms relevant to existing strategies is necessary, including the role of placebos in trials for IBS Generally, pharmacological therapies are considered efficacious if they are superior to placebos in clinical trials. ${ }^{2}$ The magnitude of the placebo response therefore has profound effects on the outcomes of these trials. Previous pharmacological trials in disorders of gut-brain interaction, including IBS, have shown that there is a substantial proportion of patients that benefits from placebo intervention. ${ }^{7}$ A previous meta-analysis ${ }^{8}$ of the placebo response in IBS showed a pooled placebo response rate of $37.5 \%(95 \%$ CI $34.4-40 \cdot 6$; with a wide range between $0 \%$ to $91.7 \%$ ). Due to the high placebo response rate in IBS trials, the assay sensitivity (ie, the ability of a trial to successfully differentiate between an efficacious and an inefficacious treatment) is generally low.

Placebo responses in IBS have received increasing attention. 'The placebo effect has been identified as a phenomenon influenced by multiple factors of the psychosocial treatment context, including patient characteristics and communication between doctor and patient, as well as the normal symptom fluctuation over time in many diseases. In the context of randomised controlled
Lancet Gastroenterol Hepatol 2021; 6: 459-73

Published Online March 22, 2021 https://doi.org/10.1016/ S2468-1253(21)00023-6 See Comment page 416

Division of Gastroenterology and Hepatology, Department of Internal Medicine, School of Nutrition and Translational Research in Metabolism, Maastricht University Medica Center, Maastricht, Netherlands (M Bosman MD TBoumans BSC,

Prof A Masclee PhD D Keszthelyi PhD); Department of Methodology and Statistics, Care and Public Health Research Institute, Faculty of Health, Medicine, and Life Sciences, Maastricht University, Maastricht, Netherlands (B Winkens PhD); Department of Medical Psychology and Medical Sociology, Faculty of Medicine, Ruhr University Bochum, Bochum, Germany (Prof S Elsenbruch PhD); Department of Neurology, University Hospital Essen, University of Duisburg-Essen, Essen, Germany (Prof S Elsenbruch); NIHR Nottingham Biomedical Research Centre, Nottingham University Hospitals NHS Trust, Nottingham, UK

(M Corsetti PhD); University of Nottingham and Nottingham Digestive Diseases Centre,

School of Medicine, University of Nottingham, Nottingham, UK (M Corsetti); Translational Research Center for Gastrointestinal Disorders, Catholic University of Leuven, Leuven, Belgium (Prof JTack PhD); Division of Gastroenterology and Hepatology, University Hospitals Leuven, Leuven, Belgium (Prof JTack); Department of Molecular and Clinical Medicine, Institute of Medicine, Sahlgrenska Academy, University of 
Gothenburg, Gothenburg, Sweden (Prof M Simrén PhD); Centre for Functional GI and Motility Disorders, University of North Carolina, Chapel Hill, NC, USA (Prof M Simrén)

Correspondence to: Dr Michelle Bosman, Division of

Gastroenterology and Hepatology, Department of Internal Medicine, School of Nutrition and Translational Research in Metabolism, Maastricht University Medical Center, 6202 AZ Maastricht, Netherlands m.bosman@ maastrichtuniversity.nl

\section{Research in context}

\section{Evidence before this study}

Trials in irritable bowel syndrome are characterised by a high placebo response (a 2010 meta-analysis showed a pooled placebo response rate of $37.5 \%$ ), which largely influences the success of these trials. However, previous systematic reviews have shown conflicting results for the factors affecting the placebo response rate in clinical trials. Additionally, these analyses predate the irritable bowel syndrome responder definition by the US Food and Drug Administration (FDA) and European Medicines Agency. We did a systematic review and meta-analysis to identify the pooled placebo response rate in pharmacological randomised controlled trials in adult patients with irritable bowel syndrome to better understand the factors affecting the placebo response rate. We searched MEDLINE, EMBASE, and the Cochrane Central Register of Controlled Trials between April 1, 1959, and April 30, 2020, using search terms "irritable bowel syndrome", "IBS", "irritable colon", "spastic colon", "spastic bowel", in combination with "placebo", and "placebo effect" with no language restrictions. Only studies that reported a dichotomous outcome of response to therapy with a minimal therapy duration of 4 weeks were included.

\section{Added value of this study}

This meta-analysis of 73 randomised controlled trials highlights different moderators that are associated with an increased pooled placebo response rate in pharmacological trials in irritable bowel syndrome. Additionally, we found a decrease in the pooled placebo response rate after the introduction of the composite FDA endpoint, but the therapeutic gain remained unaltered. These findings could help optimise trial design in irritable bowel syndrome.

\section{Implications of all the available evidence}

Based on the findings in this meta-analysis, we suggest future pharmacological trials in irritable bowel syndrome to apply a run-in period of at least 2 weeks (preferably without a placebo therapy pending further research on this topic), and a dose of one or two times a day, to minimise the placebo response rate. There is a reporting and assessment gap in factors affecting patients' treatment expectancies, causing an inadequate assessment of the influence of these factors on the pooled placebo response rate. Adequate assessment and reporting of these factors in the future is needed.

Despite the unaltered therapeutic gain after the introduction of the FDA endpoint, advantages of the FDA endpoint are its contribution to harmonisation of irritable bowel syndrome trials and also that the endpoint seems less sensitive to the sample size of the placebo group. At this point, we believe that the introduction of the FDA endpoint represents a step in the right direction to bring uniformity to irritable bowel syndrome trials, but further investigation of its performance is required. trials in IBS, study or trial characteristics, including trial duration and number of study visits, have been identified as moderators of the placebo response..$^{10}$ Several systematic reviews have attempted to identify specific moderators of the placebo response in IBS, but with conflicting results. ${ }^{8,11,12}$ Improved knowledge regarding moderators in clinical trials is therefore needed to minimise the magnitude of the placebo response in clinical trials by optimising trial designs. ${ }^{10}$ This knowledge is especially called for given the publication of the 2016 Rome IV guidance that generated substantial advances in several aspects of clinical trial design, ${ }^{2}$ and publication of the European Medicines Agency (EMA) ${ }^{13}$ and the US Food and Drug Administration (FDA) ${ }^{14}$ standards for responder definition in IBS clinical trials. As far as we know, the effects of these novel definitions and recommendations on the placebo response rate have not yet been studied, even though a large number of trials have been done since then.

Therefore, we did a systematic review and meta-analysis that aimed to characterise the pooled placebo response rate in pharmacological randomised controlled trials in patients with IBS and to identify the moderators of the magnitude of the placebo response rate.

\section{Methods}

\section{Search strategy and selection criteria}

This systematic review and meta-analysis was done in accordance with the guidance provided by the Cochrane
Handbook for Systematic Reviews of Interventions ${ }^{15}$ and PRISMA. ${ }^{16}$ The protocol is registered in PROSPERO, CRD42020170908. ${ }^{17}$ We searched the medical literature to identify potential studies using MEDLINE (April 1, 1959, to April 30, 2020), EMBASE (Jan 1, 1974, to April 30, 2020), and the Cochrane Central Register of Controlled Trials (April 1, 1959 to April 30, 2020). Foreign language papers were translated where necessary. Eligible trials were randomised controlled trials that examined the effect of pharmacological therapies compared with a control arm with a placebo (as a pill, tablet, or capsule). The participants of the study population had to be adult ( $\geq 18$ years) with the diagnosis of IBS (based on either symptom-based diagnostic criteria [ie, Rome criteria] or a physician's assessment). A minimum treatment duration of 4 weeks of active therapy was required (in line with recommendations for treatment trials for disorders of gut-brain interaction). ${ }^{2,13}$ Trials had to report a dichotomous outcome of response to therapy, in terms of global improvement or improvement in abdominal pain. The outcome had to be reported by the patient. ${ }^{2}$ The first period of crossover randomised controlled trials were eligible for inclusion if the authors provided data before crossover. We excluded trials that had treatments other than pharmacological therapies (eg, dietary interventions, food supplements, or psychological therapies), reported on treatment satisfaction as dichotomous outcome of response to therapy, ${ }^{18}$ duplicated or reanalysed previously 
obtained trial data, and any publication type that was not a full-text article (eg, conference abstract, due to incomplete data for our outcome assessment). There were no language restrictions. Corresponding authors of the studies were contacted if the full-text article was not available and to provide additional information on individual studies when required.

The search was independently done by TB and MB. A medical librarian was contacted for supervision of the search. Trials in IBS were identified using the search terms "irritable bowel syndrome" (as medical subject heading and free-text term), combined, using the set operator "OR", with "irritable colon", "IBS", "spastic colon", or "spastic bowel" (as free-text terms). These terms were then combined using the set operator "AND" with studies identified using the terms "placebo" or "placebo effect" (both as medical subject heading and free-text terms). Articles identified by the search were assessed and extracted by their abstract, independently by $\mathrm{TB}$ and $\mathrm{MB}$, according to the predefined eligibility criteria. Subsequently, all potentially relevant articles were obtained and evaluated independently by TB and MB in greater detail to assess eligibility. Disagreement between the investigators was resolved by discussion with a third investigator (DK).

\section{Data analysis}

The primary outcome assessed was the magnitude of the placebo response rate. For the primary outcome assessment, we distinguished between a global improvement responder (ie, patients reporting global improvement) after therapy with placebo, an abdominal pain responder (ie, relief of abdominal pain) after therapy with placebo, and a responder according to the composite FDA endpoint after therapy with placebo (defined as a $\geq 30 \%$ reduction in abdominal pain and increase of $\geq 1$ complete spontaneous bowel movement from baseline in the same week [IBS with constipation] or a $\geq 50 \%$ reduction in the number of days per week with at least one stool that has a consistency of type six or seven on the Bristol stool scale compared with baseline [IBS with diarrhoea] for at least $50 \%$ of the weeks of treatment)..$^{14}$ The composite FDA endpoint was also assessed separately for the abdominal pain responder (ie, $a \geq 30 \%$ reduction in abdominal pain) and for the bowel symptom responder (ie, the change in stool frequency and consistency) according to the FDA endpoint definitions. The secondary outcome assessed was the effect of various trial and patient characteristics (ie, moderators) on the pooled placebo response rate, according to the combined responder definition (ie, the primary outcome of each specific trial [either global improvement, improvement in abdominal pain, or the US FDA endpoint], because the trials were generally powered for their specific primary endpoints). The moderators assessed were identified from previous systematic reviews: year of publication, geographical setting, trial setting (single vs multicentre and primary vs secondary or tertiary care), study design (parallel vs crossover), run-in phase (duration and use of placebo), study size, randomisation ratio, mean age, sex, criteria used to define irritable bowel syndrome, subtype of irritable bowel syndrome, mean duration of diagnosis or symptoms, baseline abdominal pain, type of active therapy, duration of therapy, dosing schedule or escalating dose, number of face-to-face visits, proportion of side-effects, dropouts in the control group, and therapeutic response in the active treatment group. Data for these moderators in each trial were extracted when available.

For all included trials, data were extracted independently by TB and MB into a Microsoft Excel spreadsheet as dichotomous outcomes (responder vs non-responder). Data were extracted as intention-to-treat analyses, with dropouts assumed to be treatment failures, whenever trial reporting allowed this, in accordance with the guidance provided by the Cochrane Handbook for Systematic Reviews of Interventions..$^{15}$

The Cochrane Risk of Bias Tool was used to assess the risk of bias at the individual study level. ${ }^{19}$ This assessment was done by DK and MB independently. Disagreements were resolved by discussion. Bias was assessed as a judgement (low, unclear, or high risk of bias) for six domains of bias (sequence generation, allocation

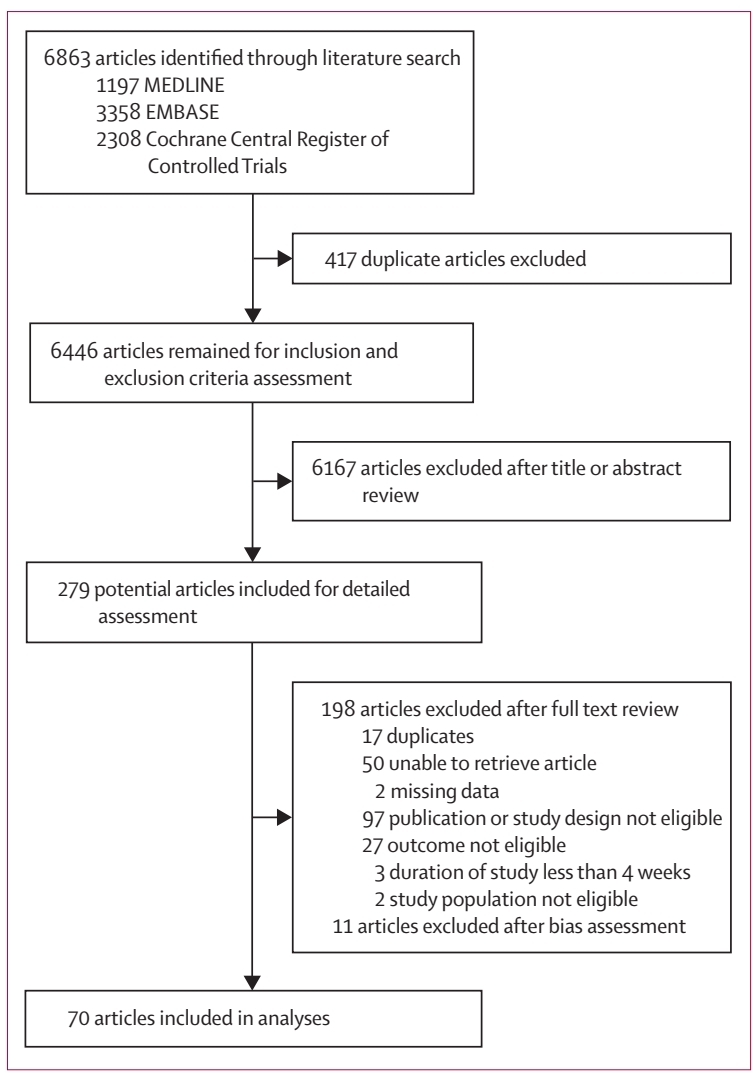

Figure 1: Study profile 


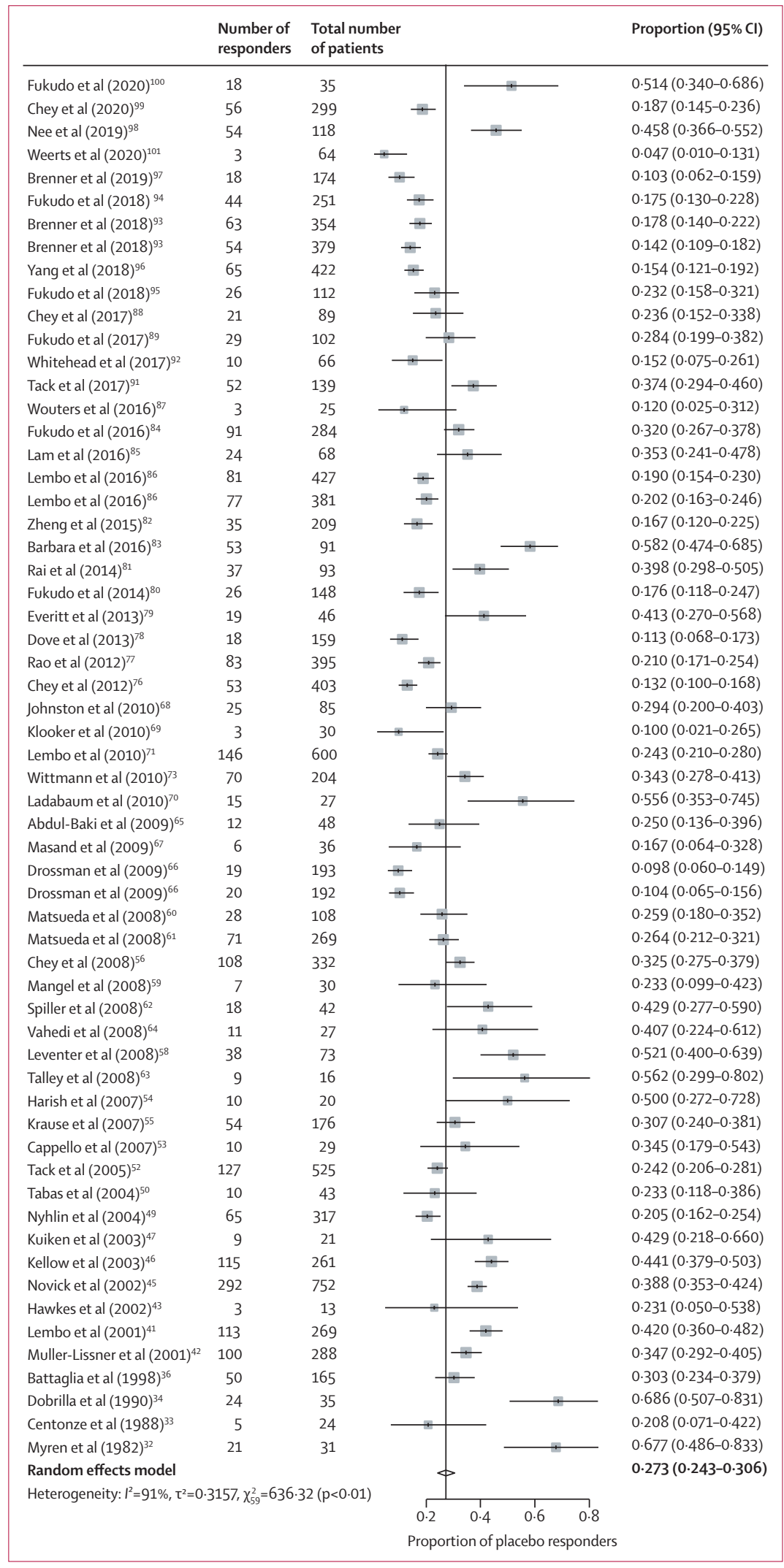

concealment, blinding, incomplete outcome data, selective outcome reporting, and other sources of bias). Criteria for the judgement of high risk of bias were either one domain with high risk of bias or four domains with unclear risk of bias. Studies with a high risk of bias were then excluded from further assessment.

Data were analysed using $\mathrm{R}$ (version 4.0.1). Data were pooled from the placebo arms of the clinical trials using a random-effects model based on logit transformation, allowing for any heterogeneity between trials. Separate analyses were run to evaluate the pooled placebo response rate across all studies for the global improvement responder, abdominal pain responder, combined endpoint (ie, the primary outcome of each specific trial [either global improvement, improvement in abdominal pain, or the US FDA endpoint], composite FDA endpoint, the FDA endpoint abdominal pain responder and the FDA endpoint bowel symptom responder, with $95 \%$ CI. Data were presented in forest plots and funnel plots were included for detecting publication bias. Some variables (ie, IBS with diarrhoea and IBS with constipation) were examined separately in a subgroup analysis, with 95\% CI. Post-hoc, we also did the previously described analyses for each of the endpoints for the intervention arms of the clinical trials to obtain the intervention response rate. To obtain the therapeutic gain, the difference between the intervention response rate and placebo response rate was calculated separately for each trial and subsequently pooled using a random-effects model.

Each moderator was examined in a separate metaregression model rather than in a combined model to avoid overfitting of data and listwise deletion (ie, some moderators were measured in one study but not in another study). Results were expressed as odds ratios with a $95 \%$ CI. Heterogeneity was evaluated using the $I^{2}$ statistic (interpreted as low heterogeneity $[<25 \%]$, moderate heterogeneity [25-50\%] and high heterogeneity [>50\%]) and homogeneity was evaluated using the $\mathrm{Q}$ statistic (with $\mathrm{p}<0 \cdot 10$ considered statistically significant). ${ }^{20} \mathrm{~A} p$ value of 0.05 or less was considered statistically significant.

\section{Role of the funding source}

There was no funding source for this study.

\section{Results}

The search strategy generated 6863 article citations, 279 of which appeared to be relevant on the basis of screening the title or abstract, or both, and were retrieved for further assessment (figure 1). Of these, 198 articles were excluded, leaving 81 eligible articles that met our inclusion criteria. The risk of bias was assessed for each study and 11 articles ${ }^{21-31}$ were excluded because of a high

Figure 2: Forest plot of the proportion of placebo responders with the endpoint of global improvement responder* *60 trials with this endpoint. 


\begin{tabular}{|c|c|c|c|c|c|c|}
\hline & \multirow{2}{*}{$\begin{array}{l}\text { Number of trials } \\
\text { with this variable }\end{array}$} & \multicolumn{2}{|l|}{ Placebo } & \multicolumn{2}{|l|}{ Intervention } & \multirow{2}{*}{$\begin{array}{l}\text { Therapeutic gain } \\
(95 \% \mathrm{Cl})\end{array}$} \\
\hline & & $\begin{array}{l}\text { Response rate } \\
(95 \% \mathrm{Cl})\end{array}$ & $1^{2}$ & $\begin{array}{l}\text { Response rate } \\
(95 \% \mathrm{Cl})\end{array}$ & $1^{2}$ & \\
\hline $\begin{array}{l}\text { Global improvement responder } \\
\text { endpoint }\end{array}$ & 60 & $27 \cdot 3 \%(24 \cdot 3-30 \cdot 9)$ & $90.7 \%$ & $42.5 \%(38.7-46 \cdot 4)$ & $95 \cdot 4 \%$ & $13 \cdot 8 \%(11 \cdot 4-16 \cdot 1)$ \\
\hline IBS-D & 20 & $27 \cdot 2 \%(22 \cdot 4-32 \cdot 7)$ & $89 \cdot 4 \%$ & $39 \cdot 8 \%(32 \cdot 7-47 \cdot 4)$ & $96.5 \%$ & .. \\
\hline IBS-C & 22 & $23 \cdot 3 \%(19 \cdot 3-27 \cdot 9)$ & $93 \cdot 2 \%$ & $37 \cdot 4 \%(32 \cdot 8-42 \cdot 1)$ & $95 \cdot 4 \%$ & .. \\
\hline $\begin{array}{l}\text { Abdominal pain responder } \\
\text { endpoint }\end{array}$ & 48 & $34 \cdot 4 \%(31 \cdot 2-37 \cdot 8)$ & $89 \cdot 4 \%$ & $46 \cdot 8 \%(43 \cdot 5-50 \cdot 2)$ & $93 \cdot 5 \%$ & $12 \cdot 0 \%(9 \cdot 3-14 \cdot 7)$ \\
\hline IBS-D & 23 & $33 \cdot 6 \%(30 \cdot 1-37 \cdot 4)$ & $81 \cdot 6 \%$ & $46 \cdot 7 \%(43 \cdot 1-50 \cdot 3)$ & $87.9 \%$ & .. \\
\hline IBS-C & 13 & $31 \cdot 5 \%(25 \cdot 1-38 \cdot 7)$ & $94.6 \%$ & $40 \cdot 1 \%(34 \cdot 4-46 \cdot 0)$ & $95 \cdot 7 \%$ & \\
\hline Combined responder endpoint & 73 & $31 \cdot 3 \%(28 \cdot 2-34 \cdot 5)$ & $91 \cdot 6 \%$ & $45.9 \%(42 \cdot 4-49 \cdot 5)$ & $95 \cdot 5 \%$ & $13.0 \%(10 \cdot 9-15 \cdot 0)$ \\
\hline \multicolumn{7}{|l|}{ US FDA endpoint responder } \\
\hline Composite & 20 & $17 \cdot 9 \%(15 \cdot 2-21 \cdot 0)$ & $82.8 \%$ & $29 \cdot 1 \%(26 \cdot 0-32 \cdot 4)$ & $88.6 \%$ & $11 \cdot 7 \%(9 \cdot 5-13 \cdot 9)$ \\
\hline IBS-D & 9 & $21 \cdot 1 \%(16 \cdot 6-26 \cdot 4)$ & $84.0 \%$ & $31 \cdot 6 \%(26 \cdot 3-37 \cdot 5)$ & $91 \cdot 1 \%$ & \\
\hline IBS-C & 10 & $15 \cdot 7 \%(12 \cdot 6-19 \cdot 4)$ & $80.9 \%$ & $27 \cdot 3 \%(23 \cdot 6-31 \cdot 4)$ & $87 \cdot 1 \%$ & \\
\hline Abdominal pain & 19 & $35 \cdot 1 \%(30.6-39 \cdot 9)$ & $89 \cdot 1 \%$ & $45 \cdot 7 \%(41 \cdot 2-50 \cdot 2)$ & $92 \cdot 4 \%$ & $10 \cdot 9 \%(6 \cdot 4-15 \cdot 5)$ \\
\hline IBS-D & 8 & $37 \cdot 0 \%(29 \cdot 5-45 \cdot 1)$ & $90 \cdot 3 \%$ & $49 \cdot 9 \%(44 \cdot 3-55 \cdot 6)$ & $88 \cdot 4 \%$ & .. \\
\hline IBS-C & 9 & $34 \cdot 6 \%(28 \cdot 4-41 \cdot 5)$ & $90.9 \%$ & $42 \cdot 7 \%(35 \cdot 7-50 \cdot 1)$ & $95 \cdot 0 \%$ &. \\
\hline Bowel symptom & 19 & $28.3 \%(23.4-33 \cdot 8)$ & $92 \cdot 7 \%$ & $42 \cdot 6 \%(37 \cdot 4-47 \cdot 9)$ & $95.0 \%$ & $13 \cdot 3 \%(10 \cdot 2-16 \cdot 5)$ \\
\hline IBS-D & 9 & $29 \cdot 2 \%(20 \cdot 9-39 \cdot 3)$ & $94 \cdot 2 \%$ & $42.8 \%(33.9-52 \cdot 2)$ & $96 \cdot 2 \%$ & \\
\hline IBS-C & 10 & $27 \cdot 4 \%(21 \cdot 6-34 \cdot 1)$ & $91 \cdot 9 \%$ & $42 \cdot 4 \%(36 \cdot 1-48 \cdot 8)$ & $93.9 \%$ & \\
\hline
\end{tabular}

risk for bias. 73 randomised controlled trials, described in 70 articles, ${ }^{32-101}$ were included in the meta-analysis. Detailed characteristics of individual trials are provided in the appendix (pp 2-4). The bias assessment of all articles is reported in the appendix ( $p 5)$. The risk of bias was low for most of the included articles (58 of the 70 articles). However, selection bias was unclear for several included articles because the allocation concealment might have been compromised by treatment-specific side-effects. Additionally, in some articles a high drop-out ratio of $1(20 \%)$ out of 5 patients was reported or the sample size calculation was unclear.

60 trials provided data for the outcome assessment of proportion of patients who were global improvement responders (figure 2; table 1; appendix p 6). The placebo response rate ranged from $4.7 \%$ to $68.6 \%$, with an overall pooled placebo response rate of $27.3 \%$ (95\% CI 24.3-30.9), with substantial heterogeneity between the trials $\left(I^{2}=90 \cdot 7 \%\right)$. The pooled intervention response rate for this endpoint was $42 \cdot 5 \%$ (95\% CI 38.7-46.4), with substantial heterogeneity between the trials $\left(I^{2}=95 \cdot 4 \%\right)$, resulting in a therapeutic gain of $13.8 \%$ (95\% CI $11 \cdot 4-16 \cdot 1)$.

48 trials provided data for the outcome assessment of proportion of patients who were abdominal pain responders (figure 3; table 1; appendix p 7). The placebo response rate ranged from $13 \cdot 3 \%$ to $63 \cdot 7 \%$, with an overall pooled placebo response rate of $34.4 \%$ (95\% CI $31 \cdot 2-37 \cdot 8)$, with substantial heterogeneity between the trials $\left(I^{2}=89 \cdot 4 \%\right)$. The pooled intervention response rate for this endpoint was $46 \cdot 8 \%(95 \%$ CI $43 \cdot 5-50 \cdot 2)$, with substantial heterogeneity between the trials $\left(I^{2}=93 \cdot 5 \%\right)$, resulting in a therapeutic gain of $12.0 \% \quad(95 \%$ CI See Online for appendix $9 \cdot 3-14 \cdot 7)$.

20 trials provided data for the outcome assessment of proportion of patients who were composite FDA endpoint responders (figure 4; table 1; appendix p 8). The overall pooled placebo response rate was $17.9 \%$ (95\% CI $15 \cdot 2-21 \cdot 0)$, with substantial heterogeneity between the trials $\left(I^{2}=82 \cdot 8 \%\right)$. The pooled intervention response rate for this endpoint was $29 \cdot 1 \%(95 \%$ CI $26 \cdot 0-32 \cdot 4)$, with substantial heterogeneity between the trials $\left(I^{2}=88 \cdot 6 \%\right)$, resulting in a therapeutic gain of $11.7 \%(95 \% \mathrm{CI}$ $9 \cdot 5-13 \cdot 9)$.

19 trials provided data for the outcome assessment of proportion of patients who were FDA endpoint abdominal pain responders (table 1). The overall pooled placebo response rate was $35 \cdot 1 \%$ (95\% CI 30.6-39.9), with substantial heterogeneity between the trials $\left(I^{2}=89 \cdot 1 \%\right)$. The pooled intervention response rate on this endpoint was $45 \cdot 7 \%(95 \%$ CI $41 \cdot 2-50 \cdot 2)$, with substantial heterogeneity between the trials $\left(I^{2}=92 \cdot 4 \%\right)$, resulting in a therapeutic gain of $10.9 \%(95 \% \mathrm{CI}$ $6 \cdot 4-15 \cdot 5)$.

19 trials provided data for the outcome assessment of proportion of patients who were FDA endpoint bowel symptom responders (table 1 ). The overall pooled placebo response rate was $28 \cdot 3 \%$ (95\% CI $23 \cdot 4-33 \cdot 8)$, 


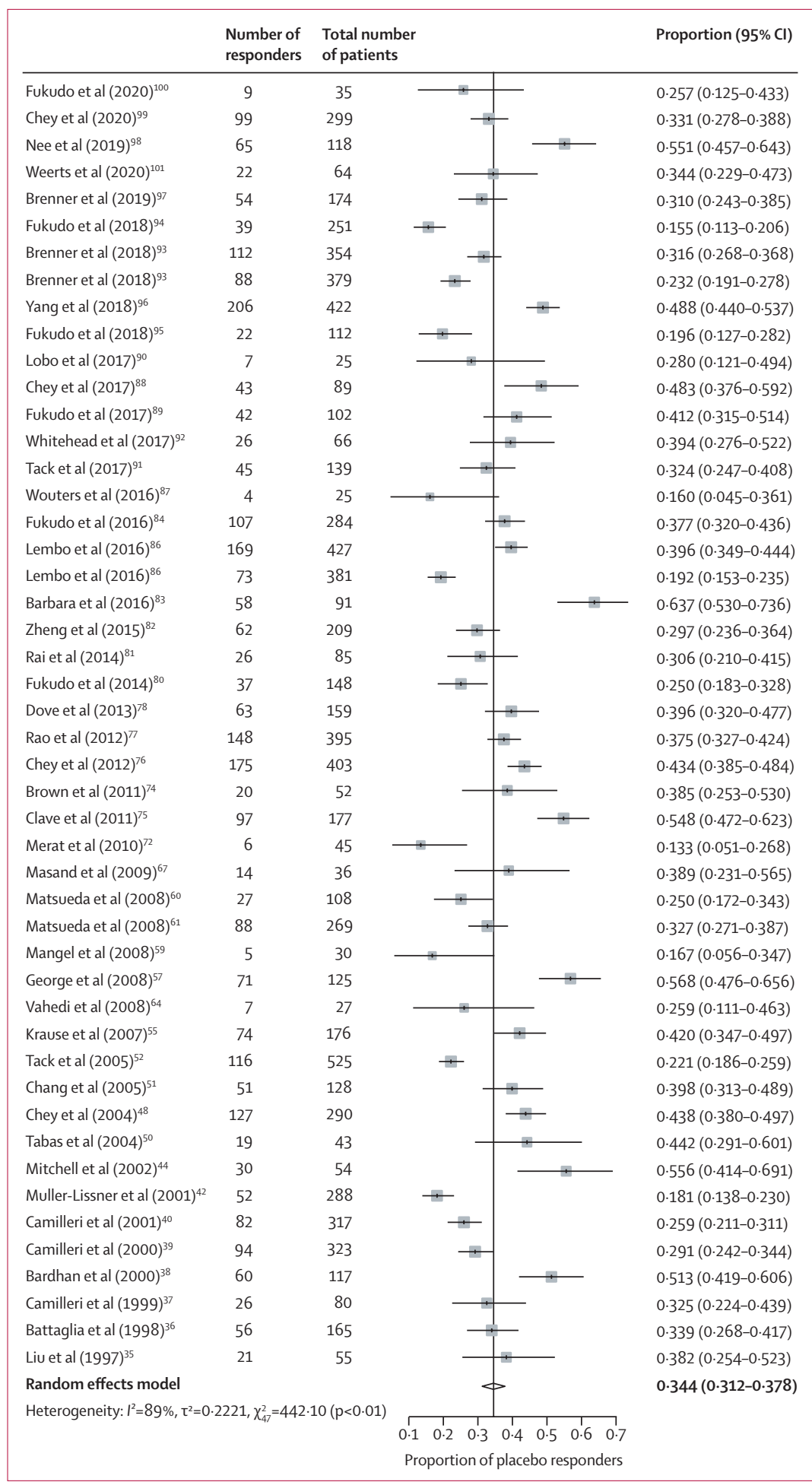

Figure 3: Forest plot of the proportion of placebo responders with the endpoint of abdominal pain responder* *48 trials with this endpoint. substantial heterogeneity between the trials $\left(I^{2}=95 \cdot 0 \%\right)$, resulting in a therapeutic gain of $13.3 \%$ (95\% CI $10 \cdot 2-16 \cdot 5)$.

For all analyses, similar results were seen in trials that assessed IBS with diarrhoea or IBS with constipation subtypes.

Figure 5 shows the response rates in the intervention group against the response rates in the placebo group as defined by the combined endpoint. There were multiple moderators associated with the magnitude of the placebo response rate as defined by the combined endpoint (table 2). There was a significant effect of the year of publication on the placebo response rate. Specifically, the trials published before 2006 (ie, corresponding to the publication of the Rome III criteria, ${ }^{2}$ which was used as a surrogate marker of the process of increased scientific rigor of clinical trial conduct and quality of reporting) had a larger pooled placebo response rate compared with trials published in or after $2006(37 \cdot 2 \%$ [95\% CI 32.7-42.0] vs $28 \cdot 9 \%$ [25.5-33.0], $\mathrm{p}=0 \cdot 032$ ). The trial location also had a significant effect on the placebo response rate. Trials done in Europe had a significantly larger pooled placebo response rate compared with trials done in America $(38 \cdot 9 \%$ [32.3-45.9] vs $25 \cdot 7 \%$ [21.3-30.5], p=0 0032) and a non-significant larger pooled placebo response rate compared with trials done in Asia $(30 \cdot 3 \%$ [25 2-35 8 ], $\mathrm{p}=0 \cdot 068)$. Some active pharmacological agents were significantly related to the placebo response rate. For IBS with diarrhoea, trials with 5-HT3 antagonists had a significant larger pooled placebo response rate compared with trials with opioid receptor agonists as the active agent

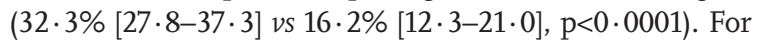
IBS with constipation, trials with 5 -HT4 agonist had a significant larger pooled placebo response rate compared with trials with secretagogues as active agent $(36 \cdot 1 \%$ [29.9-42.9] vs 20.8\% [14.5-28.9], $\mathrm{p}=0 \cdot 0030$ ).

Trial setting (single vs multicentre and primary vs secondary or tertiary care) was not significantly related to the placebo response rate. By contrast, there was a significant effect of the study design on the placebo response rate. Crossover studies had a significant lower pooled placebo response rate than parallel studies $(18 \cdot 4 \%$ [95\% CI 14.6-23.0] vs 32.8\% [29.4-36.0], $\mathrm{p}=0 \cdot 0081$ ). There was a positive association between the duration of the run-in period and the placebo response. For trials with a run-in period of 2 weeks or less, the placebo response rate was significantly higher than in trials with a run-in period of more than 2 weeks $(34 \cdot 6 \%$ [30 - 9-38 - 5] vs $19 \cdot 4 \%$ [13.7-26.6], $\mathrm{p}=0 \cdot 0001)$. However, there was no significant association between placebo run-in versus no treatment in the run-in period $(\mathrm{p}=0 \cdot 10)$. There was a significant effect of the dose schedule on the placebo response rate. Trials with a dose schedule of once or twice a day had a significantly lower pooled placebo response rate compared with trials with a dose schedule of three times a day or more $(29 \cdot 4 \%$ [26 - 2-32 - 8] vs $40 \cdot 1 \%$ $[32 \cdot 9-47 \cdot 7], p=0 \cdot 025)$. The use of an escalating dose, with substantial heterogeneity between the trials $\left(I^{2}=92 \cdot 7 \%\right)$. The pooled intervention response rate on this endpoint was $42.6 \%(95 \%$ CI $37 \cdot 4-47 \cdot 9)$, with 
mean age, the duration of irritable bowel syndrome symptoms or time since diagnosis, the proportion of patients assigned to placebo, and the level of bias were not significantly related to the placebo response rate.

Finally, we did the meta-regression analysis of numeric variables for the combined responder definition (table 3). We found a significant association between the size of the placebo group and the placebo response rate $(p=0 \cdot 016)$, indicating that larger trials were more likely to have a lower placebo response. There was no significant association when comparing the size of the placebo group with the therapeutic gain (appendix p 9). Also, the duration of therapy (against the proportion of placebo responders and the therapeutic gain), the study visits, the proportion of men, the baseline abdominal pain, and proportion of side-effects and dropouts were not associated with the placebo response rate. We did the same meta-regression analysis for the FDA endpoint responder outcome (table 3; appendix p 9). However, there was no significant relationship between any of the aforementioned variables.

\section{Discussion}

In this meta-analysis of 73 IBS randomised controlled trials, the magnitude of the placebo response rate was $27.3 \%$ using the global improvement responder definition, 34.4\% using the abdominal pain responder definition, and $17.9 \%$ using the FDA endpoint composite responder definition. When subdividing the FDA composite endpoint, the pooled placebo response rate was $35 \cdot 1 \%$ using the FDA endpoint abdominal pain responder definition and $28 \cdot 3 \%$ using the FDA endpoint bowel symptom responder definition. Studies published before 2006, with a parallel design, a run-in period of 2 weeks or less, a dose schedule of three times or more a day, studies done in Europe, and a smaller study size in the control group were significantly associated with a higher placebo response rate.

This meta-analysis was prompted by the fact that the recent introduction of novel trial endpoints and diagnostic criteria have changed the landscape for IBS trials. Several findings from our analysis are in line with the most recent meta-analysis on the subject ${ }^{8}$ (eg, higher placebo response in trials done in Europe and in trials that used a higher daily dosing schedule). Other similarities were found in the moderators that had no or only modest effects on the pooled placebo response rate-eg, the trial setting and patients' predominant stool pattern. The finding that the pooled placebo response rates in trials that used antispasmodics as the active agent were not statistically significantly higher than in trials that used peppermint oil as the active agent, is another similarity. Contrary to our study, Ford and Moayyedi found no significant effect of the year of publication on the placebo response rate, which could be related to the 10-year time gap between their and our meta-analyses.

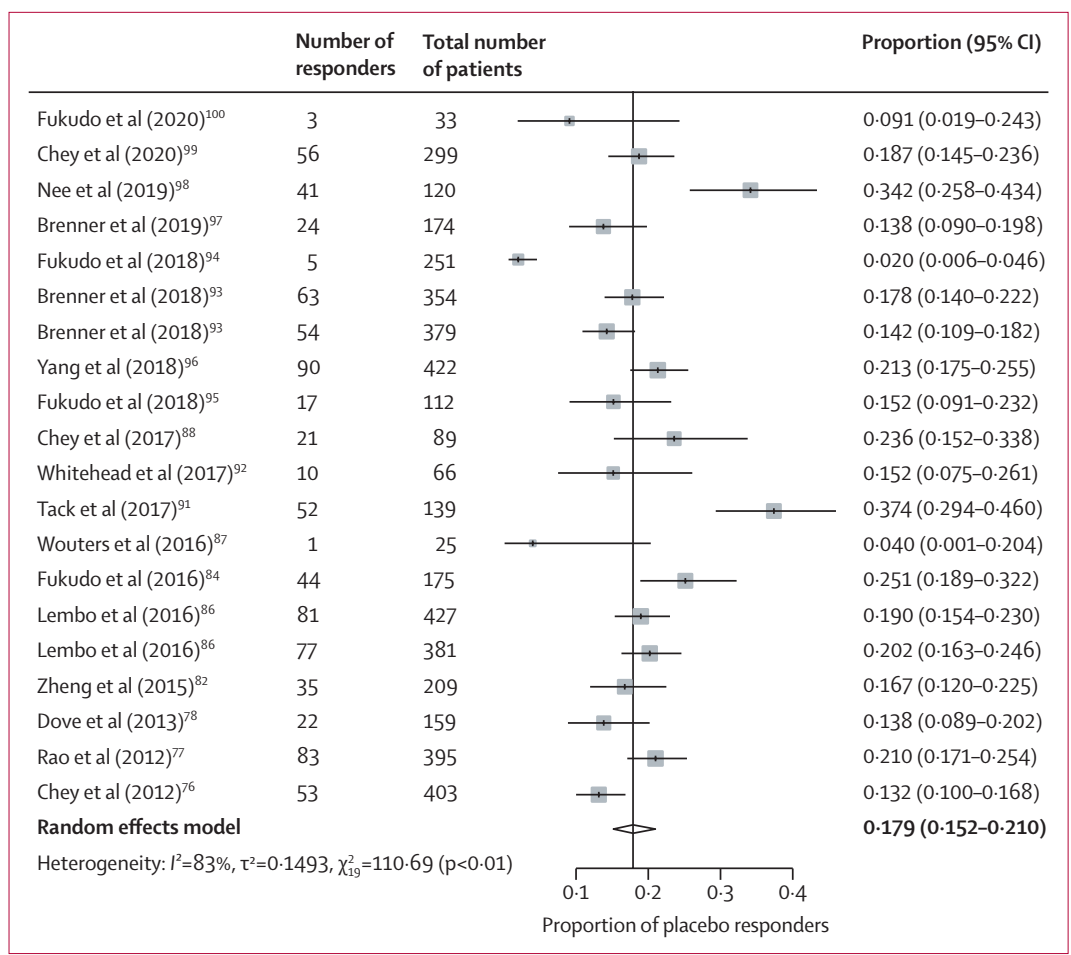

Figure 4: Forest plot of the proportion of placebo responders with the endpoint of composite FDA endpoint responder*

FDA=Food and Drug Administration. *20 trials with this endpoint.

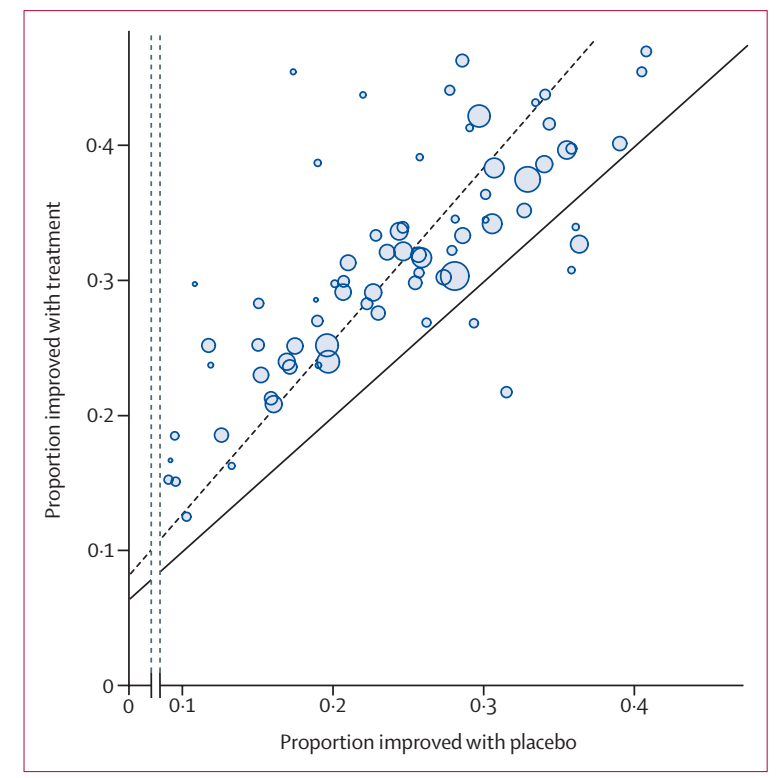

Figure 5: L'Abbe plot of the response rate, defined as the combined endpoint, in the intervention group against the response rate in the placebo group The equality line (solid line) and overall effect line (dashed line) are shown. Circle size represents sample size.

The pooled placebo response rates in this meta-analysis are lower than reported before, with pooled placebo response rates of $36.0 \%$ (95\% CI not shown), ${ }^{11} 37 \cdot 5 \%$ 


\begin{tabular}{|c|c|c|c|c|c|c|c|}
\hline & $\begin{array}{l}\text { Number of trials with } \\
\text { this variable }\end{array}$ & $\begin{array}{l}\text { Pooled placebo response } \\
\text { rate }(95 \% \mathrm{Cl})\end{array}$ & $I^{2}$ & Combined $I^{2}$ & Q statistic & $\begin{array}{l}\text { Odds ratio } \\
(95 \% \mathrm{Cl})\end{array}$ & $p$ value \\
\hline \multicolumn{8}{|l|}{ Year of publication } \\
\hline Before 2006 & 21 & $37 \cdot 2 \%(32 \cdot 7-42 \cdot 0)$ & $87 \cdot 3 \%$ & .. & .. & .. & .. \\
\hline 2006 or later & 52 & $28 \cdot 9 \%(25 \cdot 5-33 \cdot 0)$ & $92 \cdot 1 \%$ & .. & .. & .. & .. \\
\hline Before 2006 vs 2006 or later &.. & .. &.. & $92 \cdot 9 \%$ & 4.6095 & $1.47(1.03-2.08)$ & 0.032 \\
\hline \multicolumn{8}{|l|}{ Geographical location } \\
\hline Europe & 23 & $38 \cdot 9 \%(32 \cdot 3-45 \cdot 9)$ & $89 \cdot 1 \%$ & .. & .. & .. & .. \\
\hline America & 27 & $25 \cdot 7 \%(21 \cdot 3-30 \cdot 5)$ & $92 \cdot 9 \%$ & .. & .. & .. & .. \\
\hline Asia & 15 & $30 \cdot 3 \%(25 \cdot 2-35 \cdot 8)$ & $82 \cdot 8 \%$ & .. & .. & .. & .. \\
\hline Europe vs America &.. &.. & .. & $92 \cdot 8 \%$ & 8.6817 & $1.84(1.23-2 \cdot 75)$ & 0.0032 \\
\hline Europe vs Asia & .. & .. & .. & $88.0 \%$ & $3 \cdot 3224$ & $1.47(0.97-2 \cdot 22)$ & 0.068 \\
\hline \multicolumn{8}{|l|}{ Trial setting } \\
\hline Multicentre & 60 & $31 \cdot 4 \%(28 \cdot 1-34 \cdot 8)$ & $92 \cdot 8 \%$ & .. & .. & .. & .. \\
\hline Single centre & 13 & $30 \cdot 3 \%(21 \cdot 8-40 \cdot 5)$ & $72 \cdot 2 \%$ & .. & .. & .. & .. \\
\hline Primary & 6 & $40 \cdot 0 \%(28 \cdot 9-52 \cdot 3)$ & $92 \cdot 5 \%$ & .. & .. & .. & .. \\
\hline Secondary or tertiary & 32 & $34 \cdot 3 \%(29 \cdot 5-39 \cdot 5)$ & $83.9 \%$ & .. & .. & .. & .. \\
\hline Multicentre vs single centre & .. & .. &.. & $93 \cdot 5 \%$ & 0.0429 & $1.05(0.66-1.69)$ & 0.84 \\
\hline $\begin{array}{l}\text { Primary vs secondary or } \\
\text { tertiary }\end{array}$ &.$\cdot$ & .. &.$\cdot$ & $88 \cdot 4 \%$ & $0 \cdot 7017$ & $1.28(0.72-2 \cdot 29)$ & $0 \cdot 40$ \\
\hline \multicolumn{8}{|l|}{ Study design } \\
\hline Parallel & 68 & $32 \cdot 8 \%(29 \cdot 4-36 \cdot 0)$ & $91.0 \%$ & .. & .. & .. & .. \\
\hline Crossover & 5 & $18 \cdot 4 \%(14 \cdot 6-23 \cdot 0)$ & $78 \cdot 9 \%$ & .. & .. & .. & .. \\
\hline Parallel vs crossover & .. & .. &.. & $92 \cdot 6 \%$ & 7.0033 & $2 \cdot 22(1.23-4 \cdot 01)$ & 0.0081 \\
\hline \multicolumn{8}{|l|}{ Duration run-in period } \\
\hline$\leq 2$ weeks & 47 & $34 \cdot 6 \%(30 \cdot 9-38 \cdot 5)$ & $90 \cdot 4 \%$ & .. & .. & .. & .. \\
\hline$>2$ weeks & 13 & $19 \cdot 4 \%(13 \cdot 7-26 \cdot 6)$ & $96 \cdot 2 \%$ & .. & .. & .. & .. \\
\hline$\leq 2$ weeks vs $>2$ weeks & .. & .. &.. & $93 \cdot 0 \%$ & $15 \cdot 0432$ & $2 \cdot 19(1 \cdot 47-3 \cdot 26)$ & 0.0001 \\
\hline \multicolumn{8}{|l|}{ Placebo run-in } \\
\hline Yes & 3 & $46 \cdot 2 \%(31 \cdot 5-61 \cdot 6)$ & $86 \cdot 9 \%$ & .. & .. & .. & .. \\
\hline No & 70 & $30 \cdot 6 \%(27 \cdot 8-33 \cdot 9)$ & $91 \cdot 4 \%$ & .. & .. & .. & .. \\
\hline Yes vs no & .. & $\cdot \cdot$ &.. & $93 \cdot 15 \%$ & 2.693 & $1.95(0.88-4.33)$ & $0 \cdot 10$ \\
\hline \multicolumn{8}{|c|}{ Assignment ratio (placebo:intervention) } \\
\hline Balanced ratio & 41 & $33 \cdot 8 \%(29 \cdot 5-38 \cdot 4)$ & $91 \cdot 6 \%$ & .. & .. & .. & .. \\
\hline Unbalanced ratio & 32 & $28 \cdot 3 \%(24 \cdot 2-32 \cdot 7)$ & $90 \cdot 9 \%$ & .. & .. & .. &.$\cdot$ \\
\hline $\begin{array}{l}\text { Balanced ratio vs unbalanced } \\
\text { ratio }\end{array}$ &.$\cdot$ &.. &.. & $93 \cdot 1 \%$ & $2 \cdot 462$ & $1 \cdot 30(0.94-1 \cdot 79)$ & $0 \cdot 12$ \\
\hline \multicolumn{8}{|l|}{ Mean age } \\
\hline$\leq 40$ years & 17 & $34 \cdot 9 \%(27 \cdot 2-43 \cdot 4)$ & $85 \cdot 8 \%$ & .. & .. & .. & .. \\
\hline$>40$ years & 54 & $29 \cdot 9 \%(26 \cdot 6-33 \cdot 4)$ & $92 \cdot 6 \%$ & .. & .. & .. & .. \\
\hline$\leq 40$ years $v s>40$ years & .. &.$\cdot$ &.. & $93 \cdot 4 \%$ & $1 \cdot 2136$ & $1.25(0.84-1.87)$ & 0.27 \\
\hline \multicolumn{8}{|l|}{ Sex } \\
\hline$>30 \%$ of patients male & 27 & $31 \cdot 8 \%(26 \cdot 9-37 \cdot 1)$ & $85 \cdot 4 \%$ & .. & .. & .. & .. \\
\hline$<30 \%$ of patients male & 46 & $30 \cdot 9 \%(27 \cdot 2-35 \cdot 1)$ & $93 \cdot 3 \%$ & .. & .. & .. & .. \\
\hline $\begin{array}{l}>30 \% \text { of patients male } v \text { s } \\
<30 \% \text { of patients male }\end{array}$ & .. &.. &.$\cdot$ & $93 \cdot 4 \%$ & 0.0515 & $1.04(0.74-1.47)$ & 0.82 \\
\hline \multicolumn{8}{|c|}{ Duration of IBS symptoms or diagnosis } \\
\hline$\leq 5$ years & 7 & $37 \cdot 6 \%(27 \cdot 9-48 \cdot 4)$ & $89 \cdot 3 \%$ & .. & .. & .. & .. \\
\hline$>5$ years & 28 & $30 \cdot 3 \%(26 \cdot 5-34 \cdot 4)$ & $88 \cdot 4 \%$ & .. & .. & .. & .. \\
\hline$\leq 5$ years $v s>5$ years &.$\cdot$ &.. & .. & $91 \cdot 1 \%$ & $1 \cdot 7228$ & $1 \cdot 39(0.85-2 \cdot 26)$ & 0.19 \\
\hline \multicolumn{8}{|l|}{ Use of Rome criteria } \\
\hline No & 5 & $45 \cdot 4 \%(29 \cdot 6-62 \cdot 2)$ & $84 \cdot 3 \%$ & .. & .. & .. & .. \\
\hline Yes & 68 & $30 \cdot 4 \%(27 \cdot 3-33 \cdot 7)$ & $91 \cdot 8 \%$ & .. & .. & .. & .. \\
\hline \multirow[t]{2}{*}{ No vs yes } & .. &.. & .. & $93 \cdot 1 \%$ & 3.6051 & $1.90(0.98-3.69)$ & 0.058 \\
\hline & & & & & & \multicolumn{2}{|c|}{ (Table 2 continues on next page } \\
\hline
\end{tabular}




\begin{tabular}{|c|c|c|c|c|c|c|c|}
\hline & $\begin{array}{l}\text { Number of trials with } \\
\text { this variable }\end{array}$ & $\begin{array}{l}\text { Pooled placebo response } \\
\text { rate }(95 \% \mathrm{Cl})\end{array}$ & $1^{2}$ & Combined $l^{2}$ & Q statistic & $\begin{array}{l}\text { Odds ratio } \\
(95 \% \mathrm{Cl})\end{array}$ & $p$ value \\
\hline \multicolumn{8}{|l|}{ (Continued from previous page) } \\
\hline \multicolumn{8}{|l|}{ Dosage schedule } \\
\hline Three times or more a day & 14 & $40 \cdot 1 \%(32 \cdot 9-47 \cdot 7)$ & $84 \cdot 1 \%$ & & & .. & .. \\
\hline Once or twice a day & 59 & $29 \cdot 4 \%(26 \cdot 2-32 \cdot 8)$ & $91 \cdot 9 \%$ &.. &.. &.. &.. \\
\hline $\begin{array}{l}\text { Three times or more a day vs } \\
\text { once or twice a day }\end{array}$ &.. & .. & & $92 \cdot 9 \%$ & 5.0302 & $1.59(1.06-2 \cdot 38)$ & 0.025 \\
\hline \multicolumn{8}{|l|}{ Escalating dose } \\
\hline Yes & 10 & $36 \cdot 4 \%(28 \cdot 7-45 \cdot 0)$ & $66 \cdot 8 \%$ &.. &.. &.. &.. \\
\hline No & 63 & $30 \cdot 6 \%(27 \cdot 4-34 \cdot 0)$ & $92 \cdot 5 \%$ &. &.$\cdot$ &.. &.. \\
\hline Yesus no & .. & .. & .. & $93 \cdot 4 \%$ & 0.9737 & $1.28(0.78-2 \cdot 10)$ & 0.33 \\
\hline \multicolumn{8}{|l|}{ Level of bias } \\
\hline Unclear & 12 & $38.9 \%(32 \cdot 6-45 \cdot 7)$ & $69 \cdot 0 \%$ &.. & .. &.. &.. \\
\hline Low & 62 & $30 \cdot 5 \%(27 \cdot 2-33 \cdot 9)$ & $92 \cdot 4 \%$ &. &.. &.. &.. \\
\hline Unclear vs low & .. & .. & .. & $93 \cdot 1 \%$ & 1.9165 & $1 \cdot 38(0.88-2 \cdot 16)$ & 0.17 \\
\hline \multicolumn{8}{|l|}{ Active therapy } \\
\hline Antidepressant & 8 & $42 \cdot 5 \%(31 \cdot 4-54 \cdot 5)$ & $68.6 \%$ & .. &.. & .. & .. \\
\hline Antispasmodic† & 9 & $41 \cdot 7 \%(33 \cdot 6-50 \cdot 2)$ & $83 \cdot 8 \%$ &.. &.. &.. &.. \\
\hline 5-HT4 agonist $\neq$ & 11 & $36 \cdot 1 \%(29 \cdot 9-42 \cdot 9)$ & $92 \cdot 0 \%$ & .. & .. & .. & .. \\
\hline 5-HT3 antagonist $\dagger$ & 13 & $32 \cdot 3 \%(27 \cdot 8-37 \cdot 3)$ & $84 \cdot 6 \%$ &.. &.. &. &.. \\
\hline Peppermint oil & 4 & $30 \cdot 2 \%(20 \cdot 4-42 \cdot 2)$ & $61 \cdot 1 \%$ &.. &.. &.. &.. \\
\hline Secretagogues $¥$ & 12 & $20 \cdot 8 \%(14 \cdot 5-28 \cdot 9)$ & $95 \cdot 7 \%$ &.. & &.. &.. \\
\hline $\begin{array}{l}\text { Opioid receptor agonist } \\
\text { (peripherally acting) } \dagger\end{array}$ & 5 & $16 \cdot 2 \%(12 \cdot 3-21 \cdot 0)$ & $70 \cdot 1 \%$ &.. &. &.. &.. \\
\hline $\begin{array}{l}\text { 5-HT3 antagonist plus } \\
\text { antispasmodic plus opioid } \\
\text { receptor agonist (peripherally } \\
\text { acting) } \dagger\end{array}$ & 27 & $31 \cdot 5 \%(27 \cdot 1-36 \cdot 3)$ & $90 \cdot 4 \%$ &.. &.$\cdot$ &.. &.$\cdot$ \\
\hline $\begin{array}{l}\text { 5-HT4 agonist plus } \\
\text { secretagogues } ¥\end{array}$ & 23 & $27 \cdot 6 \%(22 \cdot 6-33 \cdot 2)$ & $95 \cdot 1 \%$ & .. &.. &.. & .. \\
\hline $\begin{array}{l}\text { Antispasmodic vs } \\
\text { peppermint oil }\end{array}$ &.. &. &.. & $83 \cdot 1 \%$ & $2 \cdot 1409$ & $1.68(0.84-3.34)$ & 0.14 \\
\hline $\begin{array}{l}\text { Antidepressant vs } \\
\text { peppermint oil }\end{array}$ & & &.. & $68.0 \%$ & 1.9833 & $1.74(0 \cdot 80-3 \cdot 76)$ & 0.16 \\
\hline $\begin{array}{l}\text { 5-HT3 antagonist vs opioid } \\
\text { receptor agonist } \\
\text { (peripherally acting) }\end{array}$ &. & .. &.. & $84 \cdot 0 \%$ & $16 \cdot 5223$ & $2 \cdot 50(1.61-3.88)$ & $<0.0001$ \\
\hline $\begin{array}{l}\text { Antispasmodic vs 5-HT3 } \\
\text { antagonist }\end{array}$ &. & &.. & $86.0 \%$ & 3.8122 & $1 \cdot 49(1 \cdot 0-2 \cdot 23)$ & 0.051 \\
\hline $\begin{array}{l}\text { 5-HT4 agonist vs } \\
\text { secretagogues }\end{array}$ &. &.. &.. & $94 \cdot 7 \%$ & 8.8291 & $2 \cdot 20(1 \cdot 31-3 \cdot 70)$ & 0.0030 \\
\hline $\begin{array}{l}\text { 5-HT3 antagonist plus } \\
\text { antispasmodic plus opioid } \\
\text { receptor agonist (peripherally } \\
\text { acting) vs 5-HT4 agonist plus } \\
\text { secretagogues }\end{array}$ &.. &.. &.. & $94 \cdot 7 \%$ & 0.8997 & $1.20(0.82-1.76)$ & 0.34 \\
\hline
\end{tabular}

$(34 \cdot 4-40 \cdot 6),{ }^{8}$ and $40 \cdot 2 \%(35 \cdot 9-44 \cdot 4) .{ }^{12}$ This finding could be explained by the number of trials included in this meta-analysis, the distinction between different responder definitions (in particular the novel FDA definitions), and the inclusion of a considerable number of recent trials. Our results have shown that more recent studies have a significantly lower pooled placebo response rate. This trend appears to be at odds with the increase of pooled placebo response rates observed in other disorders, such as depression, schizophrenia, and neuropathic pain. ${ }^{102,103}$ The fact that more recent clinical trials in IBS had larger sample sizes, ${ }^{10}$ and modifications in study design based on new guidelines (including the Rome III and later Rome IV criteria ${ }^{2}$ and the EMA $^{13}$ and 


\begin{tabular}{|c|c|c|c|c|c|}
\hline & $\begin{array}{l}\text { Number of } \\
\text { trials with } \\
\text { this variable }\end{array}$ & Combined $l^{2}$ & Q statistic & Odds ratio $(95 \% \mathrm{Cl})$ & $p$ value \\
\hline \multicolumn{6}{|l|}{ Primary endpoint } \\
\hline $\begin{array}{l}\text { Number of participants in } \\
\text { the placebo group }\end{array}$ & 73 & $92 \cdot 6 \%$ & $5 \cdot 7793$ & $0.999(0.998-0.9998)$ & 0.016 \\
\hline Face-to-face study visits & 55 & $94 \cdot 4 \%$ & 0.1482 & $0.98(0.87-1.09)$ & 0.70 \\
\hline Baseline abdominal pain $\dagger$ & 45 & $93 \cdot 6 \%$ & 0.5367 & $0.93(0.78-1.12)$ & 0.46 \\
\hline Proportion of side-effects & 51 & $94 \cdot 8 \%$ & 0.3682 & $1.38(0.49-3.93)$ & 0.54 \\
\hline Proportion of dropouts & 69 & $93 \cdot 4 \%$ & 1.5641 & $0.38(0.08-1.72)$ & 0.21 \\
\hline Duration of therapy, weeks & 73 & $93 \cdot 3 \%$ & 0.9809 & $0.99(0.96-1.01)$ & 0.32 \\
\hline Proportion male patients & 73 & $93 \cdot 4 \%$ & 0.4644 & $1.25(0.66-2.39)$ & 0.50 \\
\hline \multicolumn{6}{|l|}{ FDA endpoint } \\
\hline $\begin{array}{l}\text { Number of participants in } \\
\text { the placebo group }\end{array}$ & 20 & $90 \cdot 6 \%$ & 0.0019 & $1.00(0.998-1.002)$ & 0.96 \\
\hline Face-to-face study visits & 20 & $90 \cdot 7 \%$ & 0.0417 & $1.02(0.86-1.21)$ & 0.84 \\
\hline Baseline abdominal pain $\dagger$ & 18 & $89 \cdot 1 \%$ & $2 \cdot 3257$ & $0.77(0.55-1.08)$ & 0.13 \\
\hline Proportion of side-effects & 19 & $90 \cdot 7 \%$ & 0.0004 & $0.98(0.18-5 \cdot 25)$ & 0.98 \\
\hline Proportion of dropouts & 20 & $90 \cdot 6 \%$ & 0.0231 & $1.29(0.05-35.19)$ & 0.88 \\
\hline Duration of therapy, weeks & 20 & $90 \cdot 2 \%$ & 0.2065 & $1.00(0.99-1.01)$ & 0.65 \\
\hline Proportion male patients & 20 & $90 \cdot 6 \%$ & 0.0119 & $0.90(0.13-6.26)$ & 0.91 \\
\hline
\end{tabular}

FDA=US Food and Drug Administration. *The primary outcome of each specific trial, either global improvement, improvement in abdominal pain, or the US FDA endpoint. †Measured using an 11-point Numeric Rating Scale.

Table 3: Moderators with numeric variables of the placebo response rate for the composite endpoint*

FDA $^{14}$ recommendations) have favoured the trend towards lower placebo response rates in IBS. As a result, we consider it futile to compare studies before 2006 with studies done in 2006 or later.

For the following variables, our results on the association between the moderators and the placebo response rates are in line with previous studies: the significant effect of studies done in Europe, ${ }^{8,104}$ a parallel design, ${ }^{103,105}$ and a dose schedule of three times or more a day, ${ }^{8,11}$ and no significant effect of sex, ${ }^{10,106,107}$ age, ${ }^{106,107}$ and trial setting, $8,11,12$ on the placebo response rate. For study duration, ${ }^{8,10,11,108}$ disease severity, and disease duration, ${ }^{102,103,106,109,10}$ previous findings have shown incongruent results, which could be related to different selection criteria. Our results did not show a significant association between these moderators and the pooled placebo response rate. Therefore, together these findings do not support the idea that there might be placebo responders or non-responders based on individual characteristics (age, sex), which would mean that trials should select participants based on criteria to reduce placebo responses. Our findings suggest that trial design and characteristics are more important than individual characteristics to modify to minimise the placebo response rate.

We have shown that longer run-in phases are significantly associated with a lower pooled placebo response rate, in line with previous studies. ${ }^{11,12}$ However, the translation to daily practice becomes more difficult as the run-in period is extended. Therefore, we recommend future trials to apply a run-in phase of at least 2 weeks to reduce the placebo response rate. The use of a placebo run-in is questionable. ${ }^{111}$ The purpose of a placebo run-in is eliminating patients who respond to placebo during run-in and thereby decreasing placebo response rates following randomisation in the active treatment phase. It is interesting to note that, in line with studies in other disorders, ${ }^{112-114}$ our results showed no benefit of a placebo run-in on the placebo response rate. Additionally, a placebo run-in creates a selection bias and a discrepancy between the trial population and the clinical patient population..$^{106,111,115}$ Because of the risk of underestimating the overall effect size, ${ }^{2}$ and the lack of evidence for a placebo run-in decreasing the placebo response rate, there appears to be insufficient reason for the use of a placebo run-in in future trials. However, it is important to note that these results are based only on the three trials with a placebo run-in. Therefore, further research is needed to establish the exact effects of placebo run-ins on overall placebo response rates before establishing a firm recommendation.

In May, 2012, the FDA published interim endpoints for IBS trials. ${ }^{14}$ Although harmonisation of trial design in IBS was warranted, it has been a matter of debate whether the quantification of only two, albeit key, IBS symptoms (abdominal pain and disordered defecation), is able to integrate the multidimensional aspect of IBS symptoms to a sufficient degree, ${ }^{116}$ and it is has been suggested that less robust endpoints might be superior or at least equal in clinical decision making. ${ }^{117}$ Our results (table 1; figure 5) showed an approximately $10 \%$ lower placebo response rate for the composite FDA endpoint by comparison with the historically commonly applied endpoints (ie, global improvement responder endpoint). However, the intervention response rate has a similar trend, with an estimated $13 \%$ reduction for the composite FDA endpoint by comparison with the global improvement responder endpoint, resulting in a therapeutic gain nearly the same $(13.8 \%$ vs $11 \cdot 7 \%)$. Identical results were observed for the abdominal pain responder endpoints, in which the placebo response rates and intervention response rates remained the same after introduction of the FDA endpoint, resulting in no changes in the therapeutic gain. This would imply no apparent advantage of the FDA endpoint in showing the efficacy of active therapy. Conversely, the FDA endpoint seems less dependent on specific moderators, such as the sample size of the placebo group. At this point, we believe that the introduction of the FDA endpoint represents a step in the right direction to bring uniformity to IBS trials, but further investigation of the performance of this endpoint is required.

Previous studies have not shown an association between the sample size of the placebo group and the placebo response rate. ${ }^{8,11,12}$ Our findings showed such an association, which was significant, when assessing the combined responder endpoint. This association was not found for the FDA composite endpoint, which suggests that this endpoint is less sensitive to sample size. No 
association was found between sample size and therapeutic gain for any of the endpoints.

Notably, we found a higher pooled placebo response rate with the abdominal pain responder endpoints compared with the global improvement responder endpoints and the bowel symptom responder endpoint, which is in line with previous findings. ${ }^{11}$ We speculate that this finding might be because it is easier for patients to delineate an improvement specifically for abdominal pain, rather than for a much broader symptom complex with different elements, such as global improvement. Additionally, the symptom of abdominal pain is more modifiable by placebo mechanisms (cognitive factors), is more easily remembered, or is most salient to the patient, especially if the treatment information refers to improvement specifically for this symptom. Finally, the abdominal pain responder defined according to the FDA endpoint (ie, 30\% improvement in abdominal pain) might be a substantial hurdle allowing a large placebo response. ${ }^{115}$ Indeed, in some studies exploring a higher pain improvement threshold generated a bigger margin over placebo. ${ }^{86,97}$

In our analyses, we did not focus on the symptoms of bloating and abdominal discomfort because of the widespread nature and the less well defined nature of these symptoms. ${ }^{118}$ Abdominal discomfort has also been removed from the Rome IV criteria. Additionally, an improvement in the symptom of bloating or abdominal discomfort, subsequently associated with a higher pooled placebo response, is neither sensitive nor specific for IBS alone, even in trials before Rome IV, resulting in an erroneously higher placebo response rate.

As for moderators of the placebo response, treatment expectations, in terms of behavioural, psychobiological, and contextual factors (eg, conditioning, patient-clinician relationship), appear to be relevant. ${ }^{10,13,119}$ A higher pooled placebo response rate is associated with an unbalanced randomisation in multiple neurological and psychiatric conditions, ${ }^{10,106}$ and a higher number of study visits. ${ }^{11,106}$ However, our results did not show this association. An explanation might be that most trials did not report (or measure) these potential moderators. Although adequate assessment of these moderators might be difficult, we advocate for more accurate and detailed reporting of these in future trials. ${ }^{10}$ Additionally, assessing possible unblinding can also provide insight into treatment expectation, which can be accomplished, in line with FDA recommendations, ${ }^{120}$ by including a single item at the end of the trial to ask patients to identify the clinical trial arm in which they believe they participated.

Previous studies have shown that patients are more likely to report symptom improvement if they subjectively perceive an effect of the drug (including side-effects), while patients without any side-effects might believe the therapy is ineffective and for this reason might drop out of the trial. ${ }^{2,10,121,122}$ We found no such association in our results. However, these phenomena are complex and might include a multitude of underlying mechanisms including the content and mode of delivery of information during informed consent, driving a delicate balance between placebo and nocebo effects, thereby modifying treatment expectations in both positive and negative directions. ${ }^{106}$ These phenomena can also have profound effects on symptom experience, patient expectations about the active pharmacological therapy used, and reporting in the context of clinical trials. The complexity of these phenomena does not allow us to draw firm conclusions based on the current analyses. ${ }^{121,122}$

The strengths of this study include the magnitude and detailed assessment of various moderators influencing the pooled placebo response rate. Furthermore, IBS with diarrhoea and IBS with constipation were included as a subanalysis rather than a separate primary analysis given the intent of the study. It is important to note, however, that regulatory agencies currently only recognise IBS by subcategory; drugs can only be evaluated for either IBS with diarrhoea or IBS with constipation. Future scrutiny of the IBS definitions currently used by regulatory agencies is required.

There are, however, some limitations of our study. First, 12 (17\%) of the 70 articles had an unclear risk of bias, which might have influenced results. Considering the fact that we did not find an effect of the level of bias on the placebo response rate, it is more likely that these deficiencies relate to the lack of reporting of design details assessed in The Cochrane Risk of Bias Tool, rather than true design defects. Second, variability in patient behaviour during the trial period (eg, diet, exercise, stress) and clinical evolution of the disorder during studies could not be extracted from the trials but might influence the placebo response. Third, our results rely on the reporting of the included trials and as mentioned earlier, some moderators, particularly in older trials, have been inadequately reported. There is substantial heterogeneity in trial design, endpoints, and reporting, which makes pooling of results for a meta-analysis inherently difficult. Therefore, for the primary outcome of these analyses, we analysed different study endpoints separately. For the moderator analysis, we chose to perform analysis according to the primary outcomes for which the particular trial was powered, allowing some correction for differences in study design.

In conclusion, the magnitude of the pooled placebo response rate in pharmacological trials in IBS is $27.3 \%$ for the global improvement responder endpoint. After the introduction of the interim composite FDA endpoint, the pooled placebo response decreased to $17.9 \%$, but the therapeutic gain remained unaltered. However, the introduction of the FDA endpoint contributes to the harmonisation of trial designs in IBS trials and the FDA endpoint itself seems less sensitive to the sample size of the placebo group. Multiple moderators were associated with a higher pooled placebo response rate. On the basis of the our findings, we suggest future pharmacological 
trials in IBS should use a run-in period of at least 2 weeks (preferably without a placebo therapy pending further research on this topic) and a daily dose of one or two times a day to minimise the pooled placebo response rate. Sample size calculations should consider a therapeutic gain of $11-15 \%$, when using a dichotomous outcome, depending on the outcome parameter chosen. Additionally, adequate assessment and reporting in the future is needed for variables associated with treatment expectancies (both positive and negative) before and during treatment.

\section{Contributors}

DK conceptualised the review project and MB developed the study protocol under the supervision of DK. MB and TB did the literature search, screened and reviewed all the published literature, and did the data extraction. MB did the data analysis. MB and DK did the data interpretation and $\mathrm{MB}$ drafted the manuscript and prepared the tables and figures. SE, MC, JT, MS, AM, and DK provided a constructive review of the manuscript. BW provided a critical analyses of the data analysis. MB and DK have verified the underlying data. DK supervised all study phases. All authors approved the final version of the manuscript before its submission. All authors had full access to all the data in the study and have accepted responsibility to submit for publication.

\section{Declaration of interests}

SE reports grants from Deutsche Forschungsgemeinschaft (German Research Foundation), outside the submitted work. MC serves as a consultant for Sanofi, Allergan, Arena, Kiowa Kyrin, Reckitt Benckiser, outside the submitted work. JT reports personal fees from Adare, Arena, Christian Hansen, Devintec, Ironwood, Shire, Truvion, Abbott, and Menarini; and grants from Shire, Tsumura, Sofar, Mylan, outside the submitted work. MS reports grants and personal fees from Danone Nutricia Research, and Glycom; personal fees from Nestlé, Ironwood, Menarini, Biocodex, Arena, Adnovate, Shire, Tillotts, Kyowa Kirin, Takeda, Alimentray Health, AlfaSigma, and Falk Foundation; and grants from Genetic Analysis, outside the submitted work. AM reports grants from ZonMw, Will Pharma, Allegan, Grünenthal, Pentax Europe, and the Dutch Cancer Society; and financial compensation to their institution for giving scientific advice to Bayer, Kyowa Kirin, and Takeda, outside the submitted work. DK reports grants from Allergan, Will Pharma, Grünenthal, ZonMw, United European Gastroenterology, and Maag-Lever-Darmstichting, outside the submitted work. MB, BW, and TB declare no competing interests.

\section{Data sharing}

There are no individual participant data available for this review. Other documents-ie, statistical analysis plan and analytic code-will be available immediately following publication with no end date for researchers who provide a methodologically sound proposal with the purpose of achieving aims in the approved proposal. The master list of the trials included in this study is available upon request. Proposals and requests should be directed to m.bosman@maastrichtuniversity.nl to gain access; data requestors will need to sign a data access agreement.

\section{References}

1 Mearin F, Lacy BE, Chang L, et al. Bowel disorders. Gastroenterology 2016; 150: 1393-407.

2 Irvine EJ, Tack J, Crowell MD, et al. Design of treatment trials for functional gastrointestinal disorders. Gastroenterology 2016; 150: 1469-80.

3 Palsson OS, Whitehead W, Törnblom H, Sperber AD, Simren M. Prevalence of Rome IV functional bowel disorders among adults in the United States, Canada, and the United Kingdom. Gastroenterology 2020; 158: 1262-73.

4 Mönnikes H. Quality of life in patients with irritable bowel syndrome. J Clin Gastroenterol 2011; 45 (suppl): S98-101.

5 Canavan C, West J, Card T. Review article: the economic impact of the irritable bowel syndrome. Aliment Pharmacol Ther 2014 40: $1023-34$
6 Corsetti M, Whorwell P. Novel pharmacological therapies for irritable bowel syndrome. Expert Rev Gastroenterol Hepatol 2016; 10: 807-15.

7 Enck P, Klosterhalfen S. The placebo response in functional bowel disorders: perspectives and putative mechanisms. Neurogastroenterol Motil 2005; 17: 325-31.

8 Ford AC, Moayyedi P. Meta-analysis: factors affecting placebo response rate in the irritable bowel syndrome. Aliment Pharmacol Ther 2010; 32: 144-58.

9 Shah E, Pimentel M. Placebo effect in clinical trial design for irritable bowel syndrome. J Neurogastroenterol Motil 2014; 20: 163-70.

10 Elsenbruch S, Enck P. Placebo effects and their determinants in gastrointestinal disorders. Nat Rev Gastroenterol Hepatol 2015 12: 472-85

11 Pitz M, Cheang M, Bernstein CN. Defining the predictors of the placebo response in irritable bowel syndrome. Clin Gastroenterol Hepatol 2005; 3: 237-47.

12 Patel SM, Stason WB, Legedza A, et al. The placebo effect in irritable bowel syndrome trials: a meta-analysis. Neurogastroenterol Motil 2005; 17: 332-40.

13 European Medicines Agency. Guideline on the evaluation of medicinal products for the treatment of irritable bowel syndrome. 2013. https://www.ema.europa.eu/en/documents/scientificguideline/guideline-evaluation-medicinal-products-treatmentirritable-bowel-syndrome-revision-1_en.pdf (accessed Feb 15, 2021).

14 US Food and Drug Administration Center for Drug Evaluation and Research. Guidance for industry - clinical evaluation of drugs for treatment. 2012. https://www.fda.gov/media/78622/download (accessed Feb 15, 2021).

15 Cumpston M, Li T, Page MJ, et al. Updated guidance for trusted systematic reviews: a new edition of the Cochrane Handbook for Systematic Reviews of Interventions. Cochrane Database Syst Rev 2019; 10: ED000142.

16 Moher D, Liberati A, Tetzlaff J, Altman DG, Group P. Preferred reporting items for systematic reviews and meta-analyses: the PRISMA statement. BMJ 2009; 339: b2535.

17 National Institute for Health Research. PROSPERO: International prospective register of systematic reviews. 2011. https://www.crd york.ac.uk/prospero/display_record.php?ID=CRD42020170908 (accessed Feb 15, 2021).

18 Ballou S, Lembo A. Editorial: symptom improvement does not equal satisfaction with treatment for constipation. Aliment Pharmacol Ther 2020; 51: 909-10.

19 Sterne JAC, Savović J, Page MJ, et al. RoB 2: a revised tool for assessing risk of bias in randomised trials. BMJ 2019; 366: 14898.

20 West SL, Gartlehner G, Mansfield AJ, et al. Comparative effectiveness review methods: clinical heterogeneity. Rockville, MD, USA: Agency for Healthcare Research and Quality (US); 2010 .

21 Lichstein J, Dacosta Mayer J. Drug therapy of the unstable bowe (irritable colon) a 15-month double blind clinical study in 75 cases of response to a prolonged-acting belladonna alkaloid-phenobarbita mixture or placebo. J Chronic Dis 1959; 9: 394-404.

22 Moshal MG, Herron M. A clinical trial of trimebutine (mebutin) in spastic colon. J Int Med Res 1979; 7: 231-34.

23 Passaretti S, Guslandi M, Imbimbo BP, Daniotti S, Tittobello A Effects of cimetropium bromide on gastrointestinal transit time in patients with irritable bowel syndrome. Aliment Pharmacol Ther 1989; 3: 267-76.

24 Van Outryve M, Milo R, Toussaint J, Van Eeghem P. "Prokinetic" treatment of constipation-predominant irritable bowel syndrome: a placebo-controlled study of cisapride. J Clin Gastroenterol 1991; 13: 49-57.

25 Rajagopalan M, Kurian G, John J. Symptom relief with amitriptyline in the irritable bowel syndrome. J Gastroenterol Hepatol 1998; 13: 738-41.

26 Glende M, Morselli-Labate AM, Battaglia G, Evangelista S. Extended analysis of a double-blind, placebo-controlled, 15-week study with otilonium bromide in irritable bowel syndrome. Eur J Gastroenterol Hepatol 2002; 14: 1331-38.

27 Mangel AW, Chaturvedi P. Evaluation of crofelemer in the treatment of diarrhea-predominant irritable bowel syndrome patients. Digestion 2008; 78: 180-86. 
28 Chojnacki C, Walecka-Kapica E, Mokwinska M, et al. Influence of tianeptine on melatonin homeostasis and psychosomatic symptoms in patients with irritable bowel syndrome. J Physiol Pharmacol 2013; 64: $177-83$.

29 Lan L, Chen YL, Zhang H, et al. Efficacy of tandospirone in patients with irritable bowel syndrome-diarrhea and anxiety. World J Gastroenterol 2014; 20: 11422-28.

30 Ghadir MR, Poradineh M, Sotodeh M, et al. Mesalazine has no effect on mucosal immune biomarkers in patients with diarrheadominant irritable bowel syndrome referred to Shariati Hospital: a randomized double-blind, placebo-controlled trial. Middle East J Dig Dis 2017; 9: 20-25.

31 Saito YA, Almazar AE, Tilkes KE, et al. Randomised clinical trial: pregabalin vs placebo for irritable bowel syndrome. Aliment Pharmacol Ther 2019; 49: 389-97.

32 Myren I, Groth H, Larssen SE, Larsen S. The effect of trimipramine in patients with the irritable bowel syndrome. A double-blind study. Scand J Gastroenterol 1982; 17: 871-75.

33 Centonze V, Imbimbo BP, Campanozzi F, Attolini E, Daniotti S, Albano O. Oral cimetropium bromide, a new antimuscarinic drug, for long-term treatment of irritable bowel syndrome. Am J Gastroenterol 1988; 83: 1262-66.

34 Dobrilla G, Imbimbo BP, Piazzi L, Bensi G. Longterm treatment of irritable bowel syndrome with cimetropium bromide: a double blind placebo controlled clinical trial. Gut 1990; 31: 355-58.

35 Liu JH, Chen GH, Yeh HZ, Huang CK, Poon SK. Enteric-coated peppermint-oil capsules in the treatment of irritable bowel syndrome: a prospective, randomized trial. J Gastroenterol 1997; 32: 765-68.

36 Battaglia G, Morselli-Labate AM, Camarri E, et al. Otilonium bromide in irritable bowel syndrome: a double-blind, placebocontrolled, 15-week study. Aliment Pharmacol Ther 1998; 12: 1003-10.

37 Camilleri M, Mayer EA, Drossman DA, et al. Improvement in pain and bowel function in female irritable bowel patients with alosetron, a 5-HT3 receptor antagonist. Aliment Pharmacol Ther 1999; 13: 1149-59.

38 Bardhan KD, Bodemar G, Geldof H, et al. A double-blind, randomized, placebo-controlled dose-ranging study to evaluate the efficacy of alosetron in the treatment of irritable bowel syndrome. Aliment Pharmacol Ther 2000; 14: 23-34.

39 Camilleri M, Northcutt AR, Kong S, Dukes GE, McSorley D, Mangel AW. Efficacy and safety of alosetron in women with irritable bowel syndrome: a randomised, placebo-controlled trial. Lancet 2000; 355: 1035-40.

40 Camilleri M, Chey WY, Mayer EA, et al. A randomized controlled clinical trial of the serotonin type 3 receptor antagonist alosetron in women with diarrhea-predominant irritable bowel syndrome. Arch Intern Med 2001; 161: 1733-40.

41 Lembo T, Wright RA, Bagby B, et al. Alosetron controls bowe urgency and provides global symptom improvement in women with diarrhea-predominant irritable bowel syndrome. Am J Gastroenterol 2001; 96: 2662-70.

42 Müller-Lissner SA, Fumagalli I, Bardhan KD, et al. Tegaserod, a 5-HT(4) receptor partial agonist, relieves symptoms in irritable bowel syndrome patients with abdominal pain, bloating and constipation. Aliment Pharmacol Ther 2001; 15: 1655-66.

43 Hawkes ND, Rhodes J, Evans BK, Rhodes P, Hawthorne AB, Thomas GA. Naloxone treatment for irritable bowel syndrome--a randomized controlled trial with an oral formulation. Aliment Pharmacol Ther 2002; 16: 1649-54.

44 Mitchell SA, Mee AS, Smith GD, Palmer KR, Chapman RW. Alverine citrate fails to relieve the symptoms of irritable bowel syndrome: results of a double-blind, randomized, placebocontrolled trial. Aliment Pharmacol Ther 2002; 16: 1187-95.

45 Novick J, Miner P, Krause R, et al. A randomized, double-blind, placebo-controlled trial of tegaserod in female patients suffering from irritable bowel syndrome with constipation. Aliment Pharmacol Ther 2002; 16: 1877-88.

46 Kellow J, Lee OY, Chang FY, et al. An Asia-Pacific, double blind, placebo controlled, randomised study to evaluate the efficacy, safety, and tolerability of tegaserod in patients with irritable bowel syndrome. Gut 2003; 52: 671-76.
47 Kuiken SD, Tytgat GN, Boeckxstaens GE. The selective serotonin reuptake inhibitor fluoxetine does not change rectal sensitivity and symptoms in patients with irritable bowel syndrome: a double blind, randomized, placebo-controlled study. Clin Gastroenterol Hepatol 2003; 1: 219-28.

48 Chey WD, Chey WY, Heath AT, et al. Long-term safety and efficacy of alosetron in women with severe diarrhea-predominant irritable bowel syndrome. Am J Gastroenterol 2004; 99: 2195-203.

49 Nyhlin H, Bang C, Elsborg L, et al. A double-blind, placebocontrolled, randomized study to evaluate the efficacy, safety and tolerability of tegaserod in patients with irritable bowel syndrome. Scand J Gastroenterol 2004; 39: 119-26.

50 Tabas G, Beaves M, Wang J, Friday P, Mardini H, Arnold G. Paroxetine to treat irritable bowel syndrome not responding to highfiber diet: a double-blind, placebo-controlled trial. Am J Gastroenterol 2004; 99: 914-20

51 Chang L, Ameen VZ, Dukes GE, McSorley DJ, Carter EG, Mayer EA. A dose-ranging, phase II study of the efficacy and safety of alosetron in men with diarrhea-predominant IBS. Am J Gastroenterol 2005; 100: 115-23.

52 Tack J, Müller-Lissner S, Bytzer P, et al. A randomised controlled trial assessing the efficacy and safety of repeated tegaserod therapy in women with irritable bowel syndrome with constipation. Gut 2005; 54: 1707-13.

53 Cappello G, Spezzaferro M, Grossi L, Manzoli L, Marzio L. Peppermint oil (Mintoil) in the treatment of irritable bowel syndrome: a prospective double blind placebo-controlled randomized trial. Dig Liver Dis 2007; 39: 530-36.

54 Harish K, Hazeena K, Thomas V, Kumar S, Jose T, Narayanan P. Effect of tegaserod on colonic transit time in male patients with constipation-predominant irritable bowel syndrome. J Gastroenterol Hepatol 2007; 22: 1183-89.

55 Krause R, Ameen V, Gordon SH, et al. A randomized, double-blind, placebo-controlled study to assess efficacy and safety of $0.5 \mathrm{mg}$ and $1 \mathrm{mg}$ alosetron in women with severe diarrhea-predominant IBS. Am J Gastroenterol 2007; 102: 1709-19.

56 Chey WD, Paré P, Viegas A, Ligozio G, Shetzline MA. Tegaserod for female patients suffering from IBS with mixed bowel habits or constipation: a randomized controlled trial. Am J Gastroenterol 2008; 103: $1217-25$

57 George AM, Meyers NL, Hickling RI. Clinical trial: renzapride therapy for constipation-predominant irritable bowel syndrome-multicentre, randomized, placebo-controlled, double-blind study in primary healthcare setting. Aliment Pharmacol Ther 2008; 27: 830-37.

58 Leventer SM, Raudibaugh K, Frissora CL, et al. Clinical trial: dextofisopam in the treatment of patients with diarrhoeapredominant or alternating irritable bowel syndrome. Aliment Pharmacol Ther 2008; 27: 197-206.

59 Mangel AW, Bornstein JD, Hamm LR, et al. Clinical trial: asimadoline in the treatment of patients with irritable bowel syndrome. Aliment Pharmacol Ther 2008; 28: 239-49.

60 Matsueda K, Harasawa S, Hongo M, Hiwatashi N, Sasaki D. A phase II trial of the novel serotonin type 3 receptor antagonist ramosetron in Japanese male and female patients with diarrheapredominant irritable bowel syndrome. Digestion 2008; 77: 225-35.

61 Matsueda K, Harasawa S, Hongo M, Hiwatashi N, Sasaki D. A randomized, double-blind, placebo-controlled clinical trial of the effectiveness of the novel serotonin type 3 receptor antagonis ramosetron in both male and female Japanese patients with diarrhea-predominant irritable bowel syndrome. Scand J Gastroenterol 2008; 43: 1202-11.

62 Spiller RC, Meyers NL, Hickling RI. Identification of patients with non-d, non-C irritable bowel syndrome and treatment with renzapride: an exploratory, multicenter, randomized, double-blind, placebo-controlled clinical trial. Dig Dis Sci 2008; 53: 3191-200.

63 Talley NJ, Kellow JE, Boyce P, Tennant C, Huskic S, Jones M. Antidepressant therapy (imipramine and citalopram) for irritable bowel syndrome: a double-blind, randomized, placebo-controlled trial. Dig Dis Sci 2008; 53: 108-15.

64 Vahedi H, Merat S, Momtahen S, et al. Clinical trial: the effect of amitriptyline in patients with diarrhoea-predominant irritable bowel syndrome. Aliment Pharmacol Ther 2008; 27: 678-84. 
65 Abdul-Baki H, El Hajj II, Elzahabi L, et al. A randomized controlled trial of imipramine in patients with irritable bowel syndrome. World J Gastroenterol 2009; 15: 3636-42.

66 Drossman DA, Chey WD, Johanson JF, et al. Clinical trial: lubiprostone in patients with constipation-associated irritable bowe syndrome--results of two randomized, placebo-controlled studies. Aliment Pharmacol Ther 2009; 29: 329-41.

67 Masand PS, Pae CU, Krulewicz S, et al. A double-blind, randomized, placebo-controlled trial of paroxetine controlled-release in irritable bowel syndrome. Psychosomatics 2009; 50: 78-86.

68 Johnston JM, Kurtz CB, Macdougall JE, et al. Linaclotide improves abdominal pain and bowel habits in a phase IIb study of patients with irritable bowel syndrome with constipation. Gastroenterology 2010; 139: 1877-86.

69 Klooker TK, Braak B, Koopman KE, et al. The mast cell stabiliser ketotifen decreases visceral hypersensitivity and improves intestinal symptoms in patients with irritable bowel syndrome. Gut 2010; 59: 1213-21.

70 Ladabaum U, Sharabidze A, Levin TR, et al. Citalopram provides little or no benefit in nondepressed patients with irritable bowel syndrome. Clin Gastroenterol Hepatol 2010; 8: 42-48.

71 Lembo AJ, Cremonini F, Meyers N, Hickling R. Clinical trial: renzapride treatment of women with irritable bowel syndrome and constipation - a double-blind, randomized, placebo-controlled, study. Aliment Pharmacol Ther 2010; 31: 979-90.

72 Merat S, Khalili S, Mostajabi P, Ghorbani A, Ansari R, Malekzadeh R. The effect of enteric-coated, delayed-release peppermint oil on irritable bowel syndrome. Dig Dis Sci 2010; 55: $1385-90$

73 Wittmann T, Paradowski L, Ducrotté P, Bueno L, Andro Delestrain MC. Clinical trial: the efficacy of alverine citrate/ simeticone combination on abdominal pain/discomfort in irritable bowel syndrome--a randomized, double-blind, placebo-controlled study. Aliment Pharmacol Ther 2010; 31: 615-24.

74 Brown PM, Drossman DA, Wood AJ, et al. The tryptophan hydroxylase inhibitor LX1031 shows clinical benefit in patients with nonconstipating irritable bowel syndrome. Gastroenterology 2011; 141: $507-16$.

75 Clavé P, Acalovschi M, Triantafillidis JK, et al. Randomised clinical trial: otilonium bromide improves frequency of abdominal pain, severity of distention and time to relapse in patients with irritable bowel syndrome. Aliment Pharmacol Ther 2011; 34: 432-42.

76 Chey WD, Lembo AJ, Lavins BJ, et al. Linaclotide for irritable bowe syndrome with constipation: a 26-week, randomized, double-blind, placebo-controlled trial to evaluate efficacy and safety. Am J Gastroenterol 2012; 107: 1702-12.

77 Rao S, Lembo AJ, Shiff SJ, et al. A 12-week, randomized, controlled trial with a 4-week randomized withdrawal period to evaluate the efficacy and safety of linaclotide in irritable bowel syndrome with constipation. Am J Gastroenterol 2012; 107: 1714-24.

78 Dove LS, Lembo A, Randall CW, et al. Eluxadoline benefits patients with irritable bowel syndrome with diarrhea in a phase 2 study. Gastroenterology 2013; 145: 329-38.

79 Everitt H, Moss-Morris R, Sibelli A, et al. Management of irritable bowel syndrome in primary care: the results of an exploratory randomised controlled trial of mebeverine, methylcellulose, placebo and a self-management website. BMC Gastroenterol 2013 13: 68 .

80 Fukudo S, Ida M, Akiho H, Nakashima Y, Matsueda K. Effect of ramosetron on stool consistency in male patients with irritable bowel syndrome with diarrhea. Clin Gastroenterol Hepatol 2014; 12: 953-59.

81 Rai RR, Dwivedi M, Kumar N. Efficacy and safety of drotaverine hydrochloride in irritable bowel syndrome: a randomized double-blind placebo-controlled study. Saudi J Gastroenterol 2014; 20: $378-82$.

82 Zheng L, Lai Y, Lu W, et al. Pinaverium reduces symptoms of irritable bowel syndrome in a multicenter, randomized, controlled trial. Clin Gastroenterol Hepatol 2015; 13: 1285-92.

83 Barbara G, Cremon C, Annese V, et al. Randomised controlled trial of mesalazine in IBS. Gut 2016; 65: 82-90.

84 Fukudo S, Kinoshita Y, Okumura T, et al. Ramosetron reduces symptoms of irritable bowel syndrome with diarrhea and improves quality of life in women. Gastroenterology 2016; 150: 358-66.
85 Lam C, Tan W, Leighton M, et al. A mechanistic multicentre, parallel group, randomised placebo-controlled trial of mesalazine for the treatment of IBS with diarrhoea (IBS-D). Gut 2016; 65: 91-99.

86 Lembo AJ, Lacy BE, Zuckerman MJ, et al. Eluxadoline for irritable bowel syndrome with diarrhea. N Engl J Med 2016; 374: 242-53.

87 Wouters MM, Balemans D, Van Wanrooy S, et al. Histamine receptor H1-mediated sensitization of TRPV1 mediates visceral hypersensitivity and symptoms in patients with irritable bowel syndrome. Gastroenterology 2016; 150: 875-87.

88 Chey WD, Lembo AJ, Rosenbaum DP. Tenapanor treatment of patients with constipation-predominant irritable bowel syndrome: a phase 2, randomized, placebo-controlled efficacy and safety trial. Am J Gastroenterol 2017; 112: 763-74.

89 Fukudo S, Matsueda K, Haruma K, et al. Optimal dose of ramosetron in female patients with irritable bowel syndrome with diarrhea: a randomized, placebo-controlled phase II study. Neurogastroenterol Motil 2017; 29: 29.

90 Lobo B, Ramos L, Martínez C, et al. Downregulation of mucosal mast cell activation and immune response in diarrhoea-irritable bowel syndrome by oral disodium cromoglycate: a pilot study. United European Gastroenterol J 2017; 5: 887-97.

91 Tack J, Schumacher K, Tonini G, Scartoni S, Capriati A, Maggi CA. The neurokinin-2 receptor antagonist ibodutant improves overall symptoms, abdominal pain and stool pattern in female patients in a phase II study of diarrhoea-predominant IBS. Gut 2017; 66: 1403-13.

92 Whitehead WE, Duffy K, Sharpe J, Nabata T, Bruce M. Randomised clinical trial: exploratory phase 2 study of ONO-2952 in diarrhoeapredominant irritable bowel syndrome. Aliment Pharmacol Ther 2017; 45: 14-26.

93 Brenner DM, Fogel R, Dorn SD, et al. Efficacy, safety, and tolerability of plecanatide in patients with irritable bowel syndrome with constipation: results of two phase 3 randomized clinical trials. Am J Gastroenterol 2018; 113: 735-45.

94 Fukudo S, Miwa H, Nakajima A, et al. A randomized controlled and long-term linaclotide study of irritable bowel syndrome with constipation patients in Japan. Neurogastroenterol Motil 2018; 30: e13444.

95 Fukudo S, Nakajima A, Fujiyama Y, et al. Determining an optimal dose of linaclotide for use in Japanese patients with irritable bowel syndrome with constipation: a phase II randomized, double-blind, placebo-controlled study. Neurogastroenterol Motil 2018; 30: e13275.

96 Yang Y, Fang J, Guo X, et al. Linaclotide in irritable bowel syndrome with constipation: a phase 3 randomized trial in China and other regions. J Gastroenterol Hepatol 2018; 33: 980-89.

97 Brenner DM, Sayuk GS, Gutman CR, et al. Efficacy and safety of eluxadoline in patients with irritable bowel syndrome with diarrhea who report inadequate symptom control with loperamide: RELIEF phase 4 study. Am J Gastroenterol 2019; 114: 1502-11.

98 Nee J, Salley K, Ludwig AG, et al. Randomized clinical trial: crofelemer treatment in women with diarrhea-predominant irritable bowel syndrome. Clin Transl Gastroenterol 2019; 10: e00110.

99 Chey WD, Lembo AJ, Rosenbaum DP. Efficacy of tenapanor in treating patients with irritable bowel syndrome with constipation a 12-week, placebo-controlled phase 3 trial (T3MPO-1). Am J Gastroenterol 2020; 115: 281-93.

100 Fukudo S, Nakamura M, Hamatani T, Kazumori K, Miwa H. Efficacy and safety of 5-HT4 receptor agonist minesapride for irritable bowel syndrome with constipation in a randomized controlled trial. Clin Gastroenterol Hepatol 2020; 19: 538-46.

101 Weerts ZZRM, Masclee AAM, Witteman BJM, et al. Efficacy and safety of peppermint oil in a randomized, double-blind trial of patients with irritable bowel syndrome. Gastroenterology 2020; 158: $123-36$.

102 Weimer K, Colloca L, Enck P. Placebo effects in psychiatry: mediators and moderators. Lancet Pspchiatry 2015; 2: 246-57.

103 Tuttle AH, Tohyama S, Ramsay T, et al. Increasing placebo responses over time in U.S. clinical trials of neuropathic pain. Pain 2015; 156: 2616-26.

104 Bhugra D, Ventriglio A. Do cultures influence placebo response? Acta Psychiatr Scand 2015; 132: 227-30. 
105 Macedo A, Baños JE, Farré M. Placebo response in the prophylaxis of migraine: a meta-analysis. Eur J Pain 2008; 12: 68-75.

106 Enck P, Klosterhalfen S. Placebos and the placebo effect in drug trials. Handb Exp Pharmacol 2019; 260: 399-431.

107 Weimer K, Colloca L, Enck P. Age and sex as moderators of the placebo response - an evaluation of systematic reviews and meta-analyses across medicine. Gerontology 2015; 61: 97-108.

108 Spiller RC. Problems and challenges in the design of irritable bowel syndrome clinical trials: experience from published trials. Am J Med 1999; 107: 91S-97S.

109 Vase L, Vollert J, Finnerup NB, et al. Predictors of the placebo analgesia response in randomized controlled trials of chronic pain: a meta-analysis of the individual data from nine industrially sponsored trials. Pain 2015; 156: 1795-802.

110 Nierenberg AA, Østergaard SD, Iovieno N, Walker RS, Fava M, Papakostas GI. Predictors of placebo response in bipolar depression. Int Clin Psychopharmacol 2015; 30: 59-66.

111 Laursen DRT, Paludan-Müller AS, Hróbjartsson A. Randomized clinical trials with run-in periods: frequency, characteristics and reporting. Clin Epidemiol 2019; 11: 169-84.

112 Lee S, Walker JR, Jakul L, Sexton K. Does elimination of placebo responders in a placebo run-in increase the treatment effect in randomized clinical trials? A meta-analytic evaluation. Depress Anxiety 2004; 19: 10-19.

113 Sharma A, Arora M, Ubdhadiya B. Impact of placebo run-in period on relative treatment effect in generalized anxiety disorder (GAD). Value Health 2010; 13: A459.
114 Karahalios A, Herbison GP, McKenzie JE. Placebo run-in periods in anticholinergic trials are not associated with treatment effect size or risk of attrition: an empirical evaluation. J Clin Epidemiol 2020; 125: 120-29.

115 Berger VW, Rezvani A, Makarewicz VA. Direct effect on validity of response run-in selection in clinical trials. Control Clin Trials 2003; 24: $156-66$.

116 Corsetti M, Tack J. FDA and EMA end points: which outcome end points should we use in clinical trials in patients with irritable bowel syndrome? Neurogastroenterol Motil 2013; 25: 453-57.

117 Lacy BE, Lembo AJ, Macdougall JE, et al. Responders vs clinical response: a critical analysis of data from linaclotide phase 3 clinical trials in IBS-C. Neurogastroenterol Motil 2014; 26: 326-33.

118 Voudouris NJ, Peck CL, Coleman G. The role of conditioning and verbal expectancy in the placebo response. Pain 1990; 43: 121-28.

119 Lacy BE, Patel NK. Rome criteria and a diagnostic approach to irritable bowel syndrome. J Clin Med 2017; 6: E99.

120 U.S. Department of Health and Human Services FDA Center for Drug Evaluation and Research. Guidance for industry: patientreported outcome measures: use in medical product development to support labeling claims: draft guidance. Health Qual Life Outcomes 2006; 4: 79.

121 Shah E, Triantafyllou K, Hana AA, Pimentel M. Adverse events appear to unblind clinical trials in irritable bowel syndrome. Neurogastroenterol Motil 2014; 26: 482-88.

122 Colloca L, Barsky AJ. Placebo and nocebo effects. N Engl J Med 2020; 382: 554-61. 